\title{
Further Developing the Judicial System utilizing Cloud, VOIP, and Videoconferencing
}

\author{
S M Nazmuz Sakib \\ Graduate of BSc in Business Studies \\ School of Business And Trade \\ Pilatusstrasse 6003, 6003 Luzern, Switzerland \\ sakibpedia@gmail.com \\ Student of Department of Law \\ Dhaka International University \\ House \# 4, Road \# 1, Block - F, Dhaka 1213 \\ sakibpedia@students.diu.ac
}

Student of BEcon in Environmental and Resource Economics

Dhaka School of Economics

4/C Eskaton Garden Rd, Ramna, Dhaka 1000, Bangladesh.

sakib.bee5@dsce.edu.bd 


\section{Abstract}

This venture targets giving a correspondence framework that can improve the legal framework execution and cooperation and furthermore make it simple to lead execution audits. This examination depicts restricted admittance to the right legitimate data just as admittance to courts and court administrations as the essential factors that limit admittance to equity. The basic target fundamental for accomplishing the point incorporates planning an online easy to understand data framework that would improve correspondence and association between legal professionals like legal advisors and disputants. The undertaking uses a subjective methodology that zeroed in on the substance investigation of essential information. Key members were court laborers like attorneys and agents, just as court clients like disputants. Pre-plan discoveries uncovered that current legitimate data frameworks - basically court sites - neglect to recognize their crowd by treating all court clients similarly comparative with the correspondence of lawful data. Likewise, the issue of admittance to equity includes the significant expense of equity also, restricted legal data that elevates admittance to equity. Post-plan discoveries from the online overview directed after the turn of events and execution of the IT curio uncovered a powerful and productive legitimate data framework. Exploration discoveries supported the advancement of an IT antiquity that records for huge shortcomings in current legal data frameworks, for example, their failure to pass on fitting legitimate data intelligently and productively. In outline, the investigation prescribes the reception of saw control to work fair and square of certainty of court clients and the differentiation between court clients to convey the right data to the right crowd.

\section{Keywords}

Access to justice, cost of justice, judicial system, videoconferencing, judicial information system, litigants, internet technologies. 


\section{Chapter 1: INTRODUCTION}

\subsection{Chapter Introduction}

A transparent and effective judicial system is vital for a harmonious society. For several decades, the judicial system has often been perceived to only benefit the wealthy and large corporations due to the high cost of justice. This event led to the formation of Legal Services Corporation (LSC) to benefit the underprivileged society (Cabral et al., 2012). The rule of law is maintained through access to justice, which is lacking in almost all legal frameworks globally. Unfortunately, a flawed judicial system or one that lacks cohesion and efficiency has detrimental consequences to human dignity as civilization demands order, which is based on the law (Beqiraj and McNamara, 2014). With an upsurge in the global population, it is rational to assume that not everyone can access a court. Worse even, some impoverished nations have individuals who cannot afford legal representation hence limiting their access to justice. Necessarily, some economies cannot merely sustain a legal system with vast resources to meet the needs of every individual leading to the adoption of technology for better solutions. The information age has brought along several benefits, most of which involve system automation and electronic interaction platforms that have transformed the world into a global village (Theodoridis, Ragkos, and Salampasis, 2019). However, Brescia et al. (2014) argue that through technological change, dominant corporations have experienced disruption and some displaced by upcoming businesses that have utilized technology to their advantage. Disruptive technological innovation penetrates any market from the lower end before finding its way into the broader market segment. Relatively, changing the judicial system through information technology (IT) should begin from the bottom by focusing on the minor laws that affect the underprivileged society in community courts.

Contemporary advances in technology can help legal systems to leapfrog the technology pitfalls associated with traditional court processes, including the time-consuming and burdensome process of case filling. The LSC was mandated to provide legal services to 
the underprivileged community across the United States; this led to the formation of Technology Initiative Grant (TIG) in the year 2000, which streamlined the legal processes through website services (Cabral et al., 2012). An online case resolution system can help save considerable resources and time for prosecutors, litigants, court clerks, judges, and the police. For instance, litigants can make improved and tailored information available to relevant authorities to ensure that the case outcomes are accurate. Also, an online case resolution system warrants the development of a website essential for seamlessly conducting judicial processes, which forms the basis of this dissertation.

Therefore, information systems are an essential aspect of judicial reforms for many countries as they help overcome challenges such as slow case processing, poor recordkeeping, and difficulties when tracking court activities. Moreover, technologies such as voice over internet protocol (VolP), cloud, and videoconferencing can be used by legal aid organizations to hold webinars and web meetings for staff, community partners, pro bono lawyers, advisory groups, and board members. Overall, courts are increasingly employing communication technology and online information, thereby creating a need to study the consequences of such initiatives on the justice system.

\subsection{Problem Statement}

This project addresses a problem that involves limited access to relevant judicial information that should help enhance global legal processes. The weight of this issue relates to the fact that access to justice maintains access to equal human dignity and spearheads both social and global economic development (Beqiraj and McNamara, 2014). Therefore, the limited access to relevant legal information highly limits the possibility of access to justice within the judicial framework.

Data is a vital commodity, and failing to access the right information as an individual without representation by a lawyer can lead to significant problems (Wolf, 2012; Brescia et al., 2014). For instance, as a young couple who intends to build a new home, you may be approached by a mortgage firm that offers a deal which is essential for financing the 
purchase of the dream home. However, defaulting payment of the mortgage loan may have dire consequences. Without access to a lawyer or the right legal information, the mortgage firm may take advantage of you, hence limiting justice. According to Wolf (2012), legal truth in the United States equates to a crisis, and low-income people have minimal or no access to legal assistance as they are denied access to at least $80 \%$ of their legal claims. The problem stretches beyond the United States hence the existence of the International Bar Association (IBA) tasked with assisting the global legal community by influencing constitutional reform (Beqiraj and McNamara, 2014). Barriers of access to justice span across jurisdictions even with the existence of court information systems; this is an implication that the manner of implementation of such systems pauses a more significant challenge than the conduct of legal processes.

Moreover, even with an upsurge in technological advancements and transformative innovations, finding information that is specific to a particular legal scenario is still challenging. Though LSC's TIG is essential for helping low-income earners access equal justice, most low-income earners still have problems locating the information that is most useful to their particular issues. Thus, access to information may not be a problem, but accessing the right information that is capable of effecting change is where the real challenge lies (Thompson, 2015). The issue relates to information overload, which involves having so much data to process that one has no idea what information is useful to them. Possibly, existing systems in the legal sector lack effective implementation of information systems that fail to distinguish audiences during the dissemination of information. In essence, technologies such as videoconferencing and VolP may serve as the quickest means of solving the underlying problem of information overload.

Consequently, the project involves an inquiry aspect essential for selecting an optimal solution. The dissertation questions include:

1. How can improved communication between the public and the judiciary enhance the effectiveness of service delivery? 
2. Does the implementation of an enhanced communication system in the judiciary improve the geographic accessibility of the courts?

3. What is the cost and time implications of the improved communication systems on the judiciary?

4. What are the benefits and challenges associated with the implementation of an enhanced communication system for the judiciary?

\subsection{Project Aims and Objectives}

Primarily, this dissertation aims to realize a working legal information system that serves as a basis for possible improvements in judicial information systems. Considering the possibility of efficiency and transparency in the judicial system through technologies, such as VolP, cloud, and videoconferencing, this dissertation aims to provide a legal communication system through an IT artefact. The information system can enhance the judicial system performance and interaction with the public, together with providing not only a more reliable but also a faster source of legal input and review. Accordingly, the paper involves a literature review of the currently available implemented judicial information systems and solutions and develop a conceptual framework that can be evaluated and scaled in different settings. The analysis of literature and a review of existing information systems in the legal sector provided useful insight regarding possible changes to enhance and facilitate court processes. The paper involves theories of technology acceptance that correspond to the successful implementation of the IT artefact based on an understanding of how users adjust to technological advancements.

Furthermore, specific objectives were essential in realizing the aim of the study. Therefore, the targets that are congruent with the purpose of the project are as follows;

1. To facilitate a communications platform where the judiciary can provide legal information. 
2. To facilitate a communications platform where the public can access this information and interact with caseworkers.

3. To allow file-sharing by the different types of users who will interact with the system.

4. To allow chat functionalities.

5. To ascertain controlled access to public services to users through the use of credential access.

6. To develop a user-friendly communication platform in conjunction with intuitive design and layouts.

\subsection{Approach}

Table 1: Description of approaches

Approach Description

\section{Design}

The design approach adopted involves the development of a communication system that will improve the performance of the judicial system and enhance interaction with the public, coupled with providing not only a more reliable but also a faster source of legal input and review. The paper involves an exploratory approach that intensely focuses on the interests of system users, such as low-income earners who are often underprivileged in their attempts to find justice. Thus, meeting the aims and objectives of the paper involved conducting a literature review, data collection through survey method, application development, a mock trial, and finally, system implementation. 


\title{
Literature \\ The literature review is about the synthesis and analysis of secondary sources like peer-reviewed journal publications that relate the aim and objectives of the research. The study of literature involves the decomposition of external sources to understand the extent to which current information systems have proven useful in transforming the justice system; this paves the way for a better understanding of the system involved in this project.
}

\begin{abstract}
Research
The research approach employed is the qualitative approach. The exploratory approach used data collection through internet surveys, which focused on the assessment of jurisdictions and other areas in the judicial system where communication systems have been improved in the past, their success levels, and the lessons learned. This information details the basis for the development of the IT artefact. The artefact is a web-based communication system built with an API (set of codes and an interface) like Twilio, set up to enhance the communication capabilities between the public and the judicial actors. The system offers credential access, video conferencing, file sharing, and chat functionalities during video or audio conferencing.
\end{abstract}




\section{Quality Assurance \\ The application of quality assurance involved the phase of application development. Agile methodologies were the basis for managing the development process. The agile approach requires that a project is released in short phases while communicating with the client involved to ensure that the project meets its needs (Coram and Bohner, 2005). The feedback from the clients will provide evaluative information that will help in adjusting the project components accordingly.}

\section{Evaluation}

The evaluation phase involved mock trials to evaluate the applications of the framework. The success of the structure meant its performance during the mock test. The mock trials included simulations of activities that would be performed by prospective users in need of legal services. The mock trials came right before the implementation phase to ensure software efficiency during implementation.

\section{Implementation}

The implementation utilized the MoSCoW method, which ensured the successful delivery of all IT artefact. The MoSCoW methodology is a common prioritization technique used in managing projects; it assists the critical stakeholders in understanding the significance of the various initiatives associated with the project (Anon, 2020). The acronym denotes four different categories: the must-haves, the should-haves, the-could haves, and the would haves. 


\subsection{Outcome}

The project involved an exploratory approach adopting relevant information for the development of the IT artefact. Through primary data collected in the field and insight from the literature review, an appropriate system capable of reducing information overload emerged. Relatively, the data collected analyzed through a qualitative analysis approach, and it helped identify some of the significant challenges faced by underprivileged lowincome earners that experience a hard time navigating the judicial system for legal services. The development process included a conceptual framework for a communication system in the judicial sector. The IT artefact obtained was a functional web-based communication system purpose of streamlining communication within the legal system. Relatively, the outcomes of the project can now help improve compliance by defining the requirements that meet specific standards, accordance with regulation, and other benchmarks. They can also play an essential part in collecting information since some of the paperwork, and related redundant activities can now be accomplished online through a website portal courtesy of the conceptual framework.

It is necessary to reflect on the overall objective of the project due to the varying design techniques. Therefore, the design approach focused on functional design with a specific focus on the functionality of the judiciary. The strategy adopted was a user-cent red strategy intended to benefit a wide range of anyone who seeks justice or anyone who needs to file any litigations. Thus, the resulting communication system is straight forward and without any technical features that may require the intervention of a legal expert. This dissertation is an excellent source of new knowledge that can assist in implementing judiciary information systems in different jurisdictions and geographies. Altogether, the scope of the project focuses on streamlining all judicial process so that legal cases can be handled efficiently in a way that enhances public access to justice. 


\subsection{Terminology}

1. Access to justice - this is the right to justice through a legal framework in the American Constitution's Bill of Rights (Lederer, 2018).

2. Cloud - this is another term used to refer to the internet and internet platforms for distributed computing.

3. Cloud computing - this involves the use of internet platforms to provide on-demand computing services whenever and wherever needed through a pay-as-you-go basis (Ranger, 2018; Attaran, 2017).

4. Information system - this is a computing system tasked with the acquisition, processing (through analytics), storage, and distribution of information, which is essential for decision-making (Alban et al., 2019).

5. Judicial system - this refers to an adversarial system in which a litigant presents their case before a neutral entity (the jury), which used evidence to pass judgment (Silverman, n.d.). The system entails several entities like judges, lawyers, litigants, and court workers and also utilizes information systems.

6. Litigants - this refers to court users with matters that require legal attention.

7. MoSCoW - this is a common prioritization technique used in managing projects as it assists in understanding the significance of the various initiatives (Anon, 2020).

8. Videoconferencing - this is a multimedia conferencing technology that allows multiple users from different geographical locations to attend face-to-face meetings virtually (Soltanian et al., 2018).

9. VolP (Voice over Internet Protocol) - this is an internet technology that allows different users to communicate via audio through a network (Cortés-Mendoza et al., 2016). 


\subsection{Chapter Summary}

The introduction section provides background information, the problem statement, the project aim, and probable outcomes of the project. The focus of the study, which revolves around the legal systems providing legal services across the global judicial framework, is provided in the background sub-section. Additionally, the sub-section offers an insight into the importance of contemporary advances of technology on the legal systems in solving disputes. The underlying thesis that touches on the increasing employment of communication technology and online innovation by the court systems justifies the need to study the consequences of such initiatives on the justice systems. The project purposes at addressing a problem that involves limited access to relevant judicial information that should help enhance global legal processes. The finding of the study reflects the analysis of primary and secondary data. Through primary data collected in the field and insight from the literature review, an appropriate system capable of reducing information overload emerged. Relatively, the next chapter outlines the current state of the global judicial system, pointing out some significant challenges in the legal system and cloud computing resource management that addresses internet technologies. Also, the chapter includes theories that drive the adoption of technology in the implementation of the judicial information system to serve as a basis for developing the IT artefact.

\section{Chapter 2: BACKGROUND AND REVIEW OF LITERATURE}

\subsection{Chapter Introduction}

Although there are information systems that address legal concerns, the practicality and efficiency of the procedures involved are still under development since the application of information technology in the judicial system is still upcoming. Therefore, this chapter reviews some of the significant factors linked to access to justice, digital literacy, and the adoption of internet technologies such as cloud computing, VolP, and videoconferencing. Through an online information system, challenges of the judicial system can leverage internet technologies such as cloud, VolP, and videoconferencing. Therefore, states can 
also benefit from the online communication systems as a conceptual framework that serves a cost reduction and time-saving strategy. Theories of technology acceptance drive the rationale of the implementation of information systems in any legal architecture, and this chapter provides a detailed understanding of such approaches.

\subsection{Research Background}

The judicial system is in crisis as low-income earners barely have access to administrative services; this relates to the 16 million legal matters that are left unattended to every year (Wolf, 2012). Alongside the low-income earners, the majority of the moderate-income people also cannot afford to be represented by lawyers (Thompson, 2015). In essence, justice can only be a luxury for the high-income earners and the wealthy minority groups who run big corporations. Such problems of limited access to justice involve limited access to the right information at the right time. Thus, how judicial affairs run mainly depend on the information systems put in place to monitor the legal system. Relatively, the LSC mandated to provide legal services to the underprivileged community led to the formation of the TIG (Cabral et al., 2012). TIG enhances the flow of services through web technologies in the form of websites. Therefore, the induction of information systems into the judicial system through TIG paved the way for new technological advancements based on the increased demand for legal services.

Moreover, courts are adopting technical solutions to establish self-help centers and websites to provide forms, videos, and legal information. On the other hand, some courts are utilizing sites to form a collaboration with the legal aid program (Cabral et al., 2012). The obstacles to access to justice comprises factor such as societal, cultural barriers and intersectional barriers, that limit the ability for the broad public to access legal information at the same time increasing susceptibility to violation of individual rights violation, corruption and discriminatory by the legal systems (Beqiraj and McNamara, 2014). In this context, information and communication technology methods can be used for online dispute resolution 
(ODR), which significantly provides a solution to the obstacles in accessing justice (Cortes, 2019). The utility of technology makes it possible for litigants to quickly access legal information about their rights, facilitate the legal process, receive legal aid electronically, and obtain free help on civil law. Primarily, the use of information systems enhances access and effective administration of justice.

The response and reactions of litigants also influence the adoption of online case resolution systems. There is an increase in the adoption of online information and communication systems in the judicial sector hence the need to invest more time and resources in developing the necessary tools to facilitate online legal processes (Hou et al., 2017). The level of satisfaction can determine the perception of litigants towards the use of online information systems. Relatively, the simplicity of some legal disputes warrants the need for online information systems (Hou et al., 2017). Some litigants only seek access to legal information so they can stay informed on the right standard measures to engage when the need arises (Schetzer, Mullins, and Buonamano, 2002). The issue further relates to determining when hiring a lawyer is necessary as well as the level of confidence required to prevent a litigant from any possible injustice. However, it is worth noting that lawyers can still eviscerate the competitiveness of the online judicial processes and exploit lessinformed litigants (Moxley, 2015). The perception of litigants towards legal practitioners impacts the success of judicial procedures.

According to Hou et al. (2017), courts often find difficulty in attending to litigants who are not available during regular working hours; this leads to constant rescheduling of hearings and eventually burdening the judicial system in the long run. Therefore, it is reasonable for courts to adopt the online information and communication systems, such as the one addressed in this dissertation, to enhance legal proceedings and related judicial processes. Also, low turnout in courts related to the fact that some states in America have established a rising cost of justice (Oduntan, 2018; Barendrecht 2013). For instance, due to the increased rate of poverty and low GDP, Nicaragua has always found difficulty in addressing the demand for justice through affordable solutions (Barendrecht, 2013). Thus, the high cost of legal truth is the major contributing factor to injustice. However, online information 
systems offer a cost-effective way of reducing litigation costs. For instance, legal proceedings can engage videoconferencing. Therefore, financing litigations is a critical aspect of not only national but also international adjustment.

\subsection{Literature Review}

\subsubsection{Current Applications of Technology in the Judicial Domain}

The utilization of information systems reduces the economic, physical, and psychological costs of accessing courthouse and, therefore, access to justices on litigant's parts. The litigants are better equipped to communicate and resolve disputes remotely and reducing the opportunity cost of attending court sessions during regular hours (Prescott, 2017). For instance, the Illinois legal help technological platform enables a litigant to submit legal questions have access to pro bono lawyers (Cabral et al., 2012). On the other hand, a portal such as the Law help enables clients to complete a wide range of tasks, such as communicating with the court, applying for legal pro bono services, and studying court procedural expectations (Cabral et al., 2012). From a broader perspective, parties involved in litigation in the commonly used traditional physical court system were disadvantaged with the high cost of travelling from different geographical locations to access courthouse, which limited their ability to seek justice. With the introduction and utilization of information systems, litigant incurs very little economic, physical, and psychological, which improves access to justice.

Technology enhances access to legal information for practitioners, thus limiting inefficiencies in the legal sector. Legal information is an essential ingredient for accessing justice for the litigant and competent legal practitioners' performance in the judicial process (Bhardwaj, 2019). Information technology enhances access to electronic and written records for the legal practitioners, increasing their ability to articulate cases and provide proper backup for their clients in the court of law. The client is also better suited to understand their situations. Lawyers cannot provide access to justice without adequate 
legal information and the necessary tools to complete their work. Practical expertise encompasses seeking information and process information quickly while performing pro bono or public services (Hackerson, 2010). The development of the Watson, a legal search database, offers immense legal information for practitioners that can be used to look up for case law and statutes and, therefore, help legal practitioners prepare while representing their clients (High, 2012). It can be noted that technology increases access to legal information, which significantly impact on legal practitioner responsibility and subsequently affects their ability for the clients to access justices. Also, lawyers can easily carry out pro bono services without any cost implications. In summary, access to justice depends on the nature and availability of information about the case and previous cases. Technology offers a means of obtaining such information, ensuring that legal practitioners are informed and better positioned to represent their clients.

\subsubsection{Constraints of Access to Justice}

Court results are only a portion of multiple processes and procedures necessary for justice. Unfortunately, the majority of people do not get justice due to several reasons involving the high cost of justice, lack of relevant legal information, the inability to interpret available legal knowledge, and the slow process of resolving legal issues (Lederer, 2018). Therefore, access to justice in the United States mostly theoretical rather than practical as the majority of people - who are primarily low-income earners - cannot access legal assistance (Lederer, 2018; Wolf 2012). As one of the significant factors that limit access to judicial processes and legal assistance altogether, the high cost of justice causes injustice. Accordingly, very few lawyers are willing to offer pro bono services, and those who are eager are probably incompetent or not experienced enough. Relatively, Wolf (2012) demonstrates a crisis about the limited access to civil legal services; this attributes to the massive judicial vacancies and an overwhelming number of withheld cases. Therefore, it would be logical to assume that the application of information technology such as webbased internet technologies can leverage some of these problems, starting with cost reduction and judicial vacancies. Censoring Wolf (2012), the inception of web-based 
solutions for handling court issues through the TIG focuses on leveraging the insufficiency of legal practitioners. However, this does not mean that the current information systems are meeting the significant needs of all potential and current litigants. Altogether, access to legal assistance is still a crisis, not only in the United States but also globally.

Access to legal systems and legal information also limits access to justice. Lederer (2018, p. 1) stipulates that "people often do not know where to find legal rules and information about their rights, nor how to understand them if they do." Thus, failure to understand the standard policies to undertake when an individual is offended by someone else causes many people to suffer from injustice. Relatively, some companies may end up breaking laws by failing to implement their policies and procedures based on legal standards. For instance, the Health Insurance Portability and Accountability Act (HIPAA) of 1996 protects the security and privacy of patient information through HIPAA Compliance failure to which may have detrimental consequences to both individuals and organizations (Warren, 2018). However, not all employees are always vastly equipped with the necessary legal information and are, therefore, prone to making mistakes that may warrant legal actions. Some employees may also face injustice from their managers due to insufficient legal details or access to a judicial system. Altogether, the limited access to justice as well as lack of legal knowledge about how the judicial system works place most people at a vulnerable position

of injustice.

\subsubsection{Digital Literacy}

Digital literacy involves how efficient people can use internet technologies and services on websites to accomplish their legal needs. Despite the varied opinion regarding the definition of digital literacy, Bauer and Ahooei (2018) argue that it is the ability to utilize the advantages of the internet. Thus, an individual who is internet literate has some background knowledge on how information travels over the internet; this would be the minimum requirement for them to utilize the advantages of the internet as a tool. Also, as may people delve into the cyberspace, cybersecurity continues to be a significant concern and creates 
the need to redefine digital literacy. Relatively, the perception of digital literacy as the ability to use digital technologies is a simplistic approach since the concept spans diverse meanings ranging from sophisticated internet technologies and the ability to utilize internet resources securely and cautiously (Bauer and Ahooei, 2018). Therefore, someone who does not have the skill to protect their online privacy is susceptive to cyberattacks, such as malware attacks. Eventually, this raises complications regarding the confidentiality of the general population in information systems.

According to Hou et al. (2017), digital literacy may affect how people perceive fairness in egovernment programs. Specifically, socio-technological factors influence how people perceive the outcomes of a judicial process as well as how fair they think the process is. For instance, it is highly likely that an individual who is well vast with digital literacy may have more faith in a legal process conducted over the internet. However, for someone who barely understands the infrastructure of the internet and its basic transaction processes, their confidence in internet-based information systems may be primarily determined by the status quo. In essence, if such inexperienced users learn of complaints regarding fraudulent activities over the internet, they tend to avoid (and lose trust to some extent) information systems, such as e-government. The lack of confidence in information systems may further attribute to the concept of cybersecurity as most internet users in the general population lack essential skills to protect their online presence and user privacy (Trepte et al., 2015; Barrett-Maitland and Lynch, 2020). Essentially, the limiting factor of internet privacy protection literacy amongst most citizens is still a significant concern that stands on the way of successful implementation of judicial information systems.

Furthermore, the essence of digital literacy in this study is its ability to help improve communication between the public and the judiciary. Therefore, litigants with digital literacy levels are likely to have more trust in judicial information systems just as they are likely to trust e-government systems, as justified by Hou et al. (2017). The level of confidentiality attributed to judicial information systems also relate to procedural justice frameworks. Hou et al. (2017) stipulate that procedural justice frameworks determine the level of satisfaction of a litigant based on how fair they perceive the procedure used to deliver justice. 
Respectively, if the litigant thinks that the process of justice is unfair and unjust, then they cannot trust outcomes that are against them, or rather, negative results. A similar principle applies to judicial information systems, which means that the success of judicial information systems lies in convincing people that information systems can be trusted. Thus, to design an efficient legal information system is to create a reliable and transparent approach as these are the prerequisites of access to justice in the judicial system. However, there is still hope since almost all, if not all, modern learning institutions currently integrate IT into schools (Sarkar, 2012). IT literacy, which supports digital literacy, is achieved through strategies such as like inception of e-learning and making it compulsory for all learners to take introductory computer courses through new training models (Talebian, Mohammadi, and Rezvanfar, 2014). Altogether, with the current IT-based curriculums in place, people can enjoy the services of judicial information systems even with limited physical courts.

\subsubsection{Significance of Court Websites and Related Information Systems}

The interactivity of legal-based websites and remote assistance software helps the user navigate the search of legal self-help resources and provide consultation services on how they can contact lawyers for referral services (Cabral et al., 2012). The ease of availability of legal information and services without physical contact cost-effectively tends to meet the legal needs of both physically challenged person and the needs of low-income people. For instance, the TIG program has created over 525 projects of legitimate aid websites that offer legal aid resources (Staudt and Medeiros, 2012). The LSC founded the TIG program that utilizes the internet's power to address access to justice for physically challenged and low-income earners.

Litigants and legal practitioners use the court system websites and related information systems to make predictions on settlement procedures, judicial decisions, and results of claims. Also, court system websites and associated information systems guarantee litigants and legal practitioners a close detection of fraud and abuse against individuals the court supervises. Split-Up Systems involving rule-based reasoning in connection to neural networks prevail in Australian Law Courts dealing with family matters (Zeleznikow, 2016). 
The systems permit predicting results for asset claims, divorce, and related family law disputes (Zeleznikow, 2016). Litigants and legal practitioners use the Split-Up Systems to back their decision making, hence enabling them in the identification of properties that should be stated in a settlement, and determine the percentage of the collective contribution that each member is entitled to get. Zeleznikow (2016) further affirms that Split-Up Systems provide a discretionary judicial decision grounded on various factors such as resource amount, contributions, and future demands. Also, predictions form the formal evidence submitted in the claim and help determine the probable outcome and potential occurrences of individual justices (Kleinberg et al., 2018). Relatively, most technology companies claim to predict possible decisions by judges through artificial intelligence (AI) (Kleinberg et al., 2018). Therefore, litigants and legal practitioners use court system websites and information systems to predict how a court resolves a case.

Litigants and legal practitioners use us court websites and related information systems to identify and address legal needs and systematize service or link them to a legally authorized service provider. States worldwide have established guidelines aiming at clearing criminal records for citizens (Calvert and Bruno, 2010). Courts have websites and system applications where litigants and legal practitioners can automatically spot and track criminal records of an individual. According to Rostain (2019), the Maryland Volunteer Lawyers Service developed a suite of tools that helped the legal practitioners within the organization to identify problems of their clients through criminal record history and available data. The organization made the Expungement tool that allowed its clients to check their criminal records and submit a clearance request. Dispute resolution through legal information systems has grown in the recent past. Many online dispute resolution websites act as streamlining and collaboration platforms for litigants and legal practitioners (Sela, 2018). Online dispute resolution platforms such as the British Columbia Civil Resolution use AI to sort litigants based on their cases and legal practitioners according to their expertise (Salter and Thompson, 2016). Accordingly, the sorting of litigants and legal practitioners forms the basis of automated decision-making and settlement subject to the case ruling. Altogether, 
court information systems can systemize the needs of litigants and link them to legal service providers.

Furthermore, in the United States, courts have a massive engagement in developing Al applications of websites for expungement. The Code of America uses datasets from California courts to ensure automatic identification of criminal issues, expungement of qualified records, and make elimination of the necessity of an individual to apply (Loyle and Binningsbo, 2018). The Al application suggested for some of the judicial information systems in the United States incorporation acts as a classifier that powers referral bots and a translator to problem stories of people (Loyle and Binningsbo, 2018). Therefore, the court system aims at developing an application that automatically detects legal claims in the description of people concerning their life problems. Also, sharing the issues and related information through the court system website is considered essential. Necessarily, Al applications can organize problem stories of litigants or court users into legal advisory systems and reduce information overload within the court system.

\subsection{Theory}

The successful implementation of internet technologies in the judicial system involves a user IT adoption models and human behavior. The theories covered in this section include technology acceptance models purposed to establish an understanding of the improvement of the judicial system using the cloud, VolP, and videoconferencing. The theories on technology acceptance in the literature are the Theory of Reasoned Action (TRA) and the Diffusion of Innovations (DOI).

\subsubsection{Theory of Reasoned Action (TRA)}

\subsubsection{Concept of TRA}

According to the TRA, the behavior of an individual is determined by their intentions to perform an act and that their plans reflect their attitude towards the behavior (Silverman et al., 2016). Regarding the application of the theory to IT adoption, Palos-Sanchez, Arenas- 
Marquez, and Aguayo-Camacho (2017) argue that someone only intends to use particular technology based on their attitude towards technology.

\subsubsection{Controversy}

In 1967, Martin Fishbein introduced the TRA, which was later extended by both Fishbein and Icek Ajzen in 1980 (Trafimow, 2009). As much as the TRA has been leading in the field of social psychology for decades, Trafimow (2009) postulates that the theory makes risky predictions based on controversy about the definition of attitude. Nguyen et al. (2018) identifies the constructs of TRA as behavioural attitude, subjective norms, and perceived behavioural control. If subjective norms and attitudes are highly favorable and perceived behavioural control is excellent, the intention to perform a behavior will also be high, hence suggesting a direct correlation between the constructs of TRA and intention. Censoring Trafimow (2009), the misinterpretation of any of the three constructs could compromise the theory as a technology acceptance model. Notably, the TRA was derived based on the assumption that one has voluntary control over their behavior. However, the validation of a belief as such is quite challenging. It is logical to assume that the volition of an actor may be circumstantial.

\subsubsection{Application of the TRA}

In practice, for someone who hates online transactions because they have experienced a robbery in the past through an e-commerce platform, their reluctance, and negative attitude towards purchasing products online is justified. Also, the intention is an excellent predictor of an individual's behavior as it hosts the confidence that a particular action will result in an intended outcome. Therefore, in the context of judicial information systems, the TRA supports the likelihood of success when internet literate litigants are involved. The subjective norms, in this case, would be the constraints of access to justice the judicial system such as a limited number of legal practitioners, high costs of prosecution, and the low turnout of litigants due to conflicting time schedules. Perceived control would be the ability of litigants and legal practitioners to utilize internet technologies such as VoIP and 
videoconferencing through the IT artefact. Finally, the attitude involved will engage the liking of the judicial system or even the web-based IT artefact.

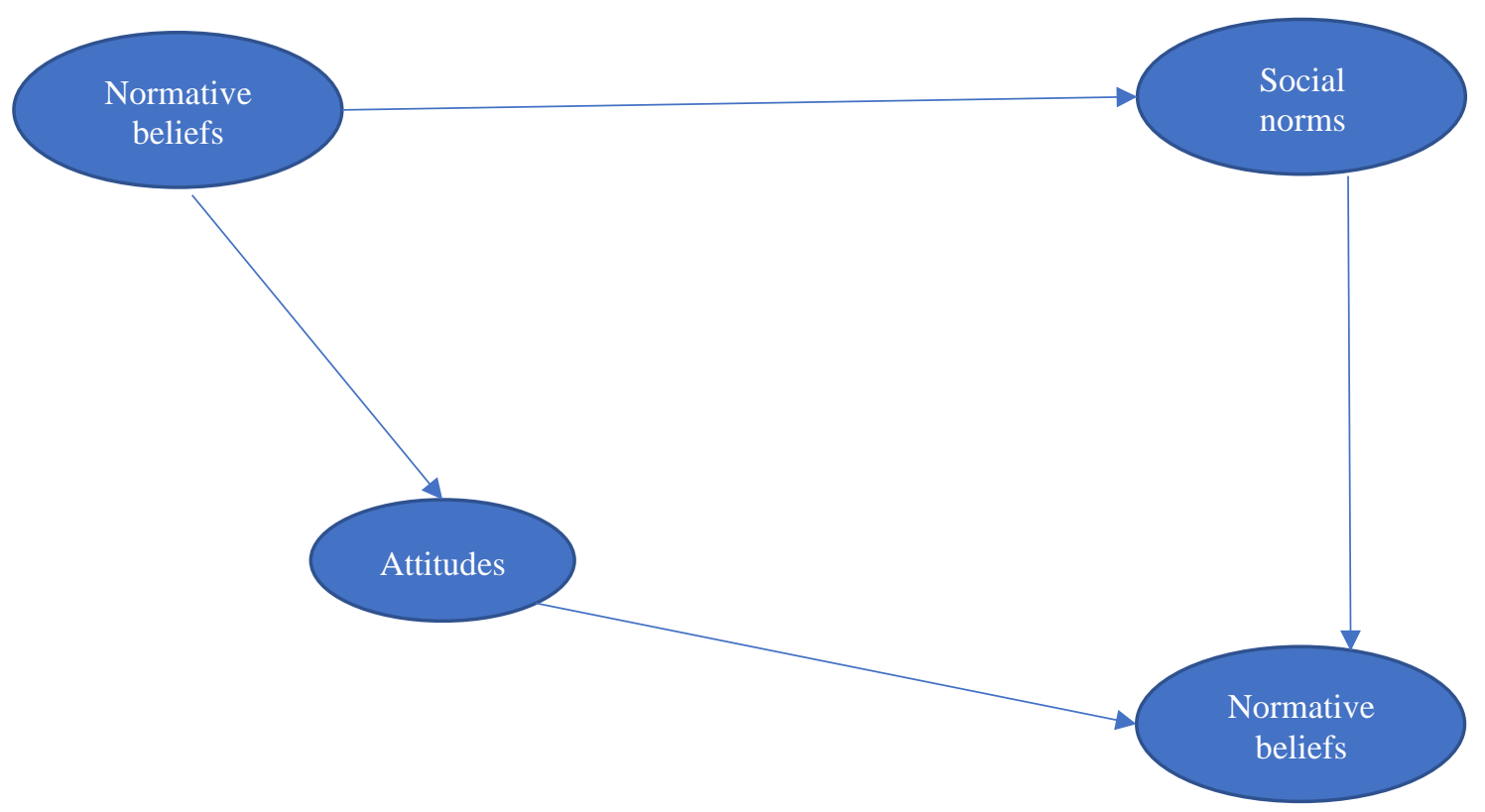

Figure 1: TRA conceptual model

\subsubsection{Diffusion of Innovations (DOI)}

\subsubsection{The Concept of DOI}

DOI justifies why, how, and the degree of spread of new ideas and technology at both individual and company level (Palos-Sanchez, Arenas-Marquez, and Aguayo-Camacho, 2017). Based on the concept of DOI, innovations transmit through social interactions over time. Therefore, at an individual level, people tend to exchange innovative ideas as they interact in their small social groups, and the views eventually extend to new social groups. Regarding the spread of creative ideas at company levels, variables like leadership, organizational structure, and external characteristics play a critical role in the range of innovations (Palos-Sanchez, Arenas-Marquez, and Aguayo-Camacho, 2017). Indubitably, the theory of DOI takes time to read multiple audiences or entities. Also, an argument by Brescia et al. (2014) reveals that big organizations have faced disruption and sometimes replacement by small organizations that are willing to adopt theories of technology acceptance, and DOI could be one of them. Thus, the diffusion of innovations, as the theory 
suggests, is dependent on how and why people and business entities are willing to apply new ideas or innovative technologies into their lives and current systems, respectively.

\subsubsection{Application of the DOI Theory}

The adoption of the DOI theory involves variables like individual factors, organizational structure, and external characteristics (Palos-Sanchez, Arenas-Marquez, and AguayoCamacho, 2017). Also, the implementation of the DOI theory relates to the assumption that most companies hesitate to adopt certain technologies like cloud technology until they are entirely confident that related uncertainties like security and standardization experience a significant reduction. In the context of judicial systems, change can begin to take place at an individual level and within the community courts. That is, the theory would apply to litigants and entities that run the local courts before the effects of change in judicial management through information systems rise to the federal courts.

Fundamentally, the idea resonates with a philosophical perspective of Brescia et al. (2014), which speculates the rise of innovation from a small organization to large corporations through social interactions. The authors reveal the demise of large corporations that have fallen or lost to startups due to their rigidness when it comes to the adoption of new ideas. It is a rational approach considering that big corporations have a lot to lose when they decide to invest in an unstable technological innovation relative to startups. However, resistance to innovative change has its fair share of consequences. Therefore, a synthesis of the DOI theory suggests that technological innovation through information systems in the judicial system is more likely to thrive at the lower level - in community courts or local courts - than at a higher level (in federal courts). 


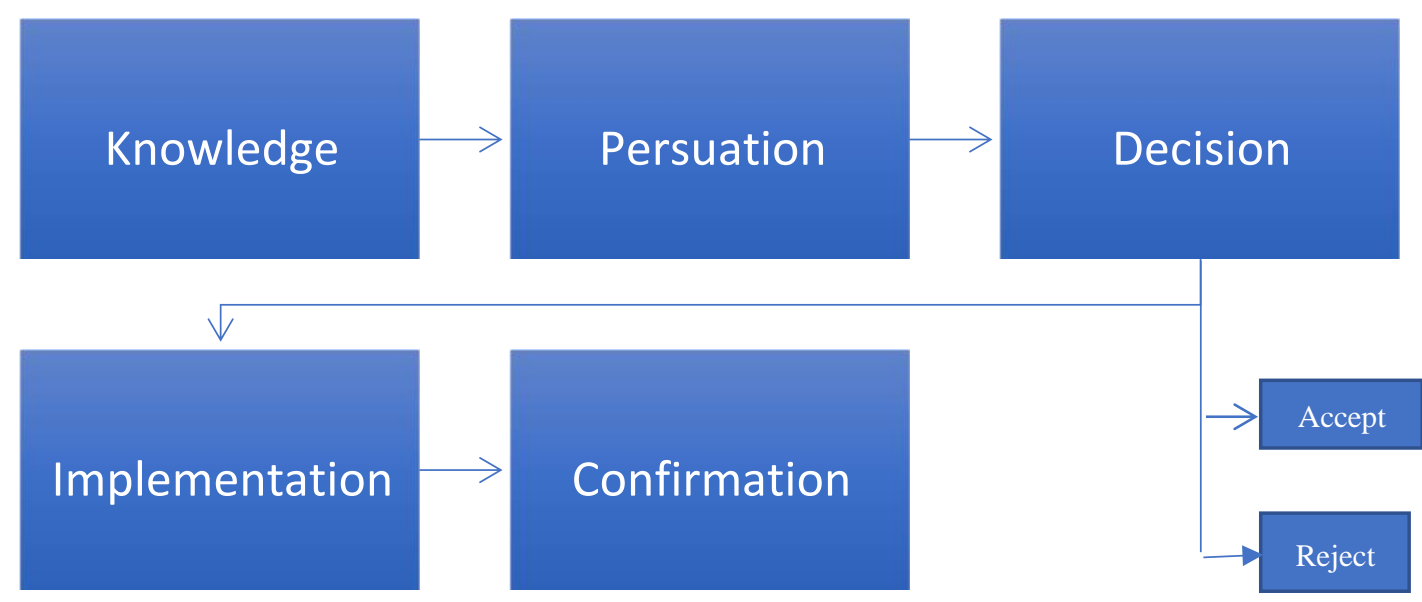

Figure 2: DOI conceptual model

\subsection{Chapter Summary}

The literature review section highlights the current state of the global judicial system, pointing out some significant challenges, such as constraints of access to justice. The high cost of justice, lack of relevant legal information, the inability to interpret available legal knowledge, and the slow process of resolving legal issues are some of the factors that limit access to justice in the country. Digital literacy is yet another concern in the status quo regarding the legal system. That is, it is troubling that some litigants may be lacking the right information in pursuit of justice due to difficulty in interpreting and comprehending some internet resources like court websites. Finally, the body of literature relates to two technology appliance models: The TRA and the DOI. However, the literary analysis only carries substantial weight when backed up with primary data, which needs a practical approach. The next chapter outlines the procedure used to obtain primary data and also covers the aspects of the design and implementation of the IT artefact. 


\section{Chapter 3: ANALYSIS AND DESIGN}

\subsection{Chapter Introduction}

The research aimed to provide a communication system that can enhance the judicial system performance and interaction and also make it easy to conduct performance reviews. The underlying objective essential for achieving the aim included designing a web-based user-friendly information system that would enhance communication and interaction between judicial practitioners like lawyers and litigants. The research method involved a qualitative approach that accounted for the two technology acceptance models - the TRA and DOI. Therefore, this chapter purposes of describing the research approach and design methodology adopted. The chapter also entails an analysis and design of the IT artefact presented as a working prototype.

\subsection{Project Specification}

Limited access to relevant judicial information necessitates this project. Despite the existence of court websites and other information systems, several litigants still have a problem access justice. This project aims to streamline and enhance access to administrative services and, eventually, legal truth. Therefore, improving the legal system through a functioning prototype in the form of an IT artefact forms the basis of this project. The IT artefact, which is a web-based communication system: one that is built with an API (set of codes and an interface) like Twilio. The system enables the following functionalities: credential access, video conferencing, file sharing, and chat functionalities.

The project was achieved by first establishing and understanding existing judicial processes and systems involved through literature analysis and primary data. Thus, both the collection of primary data and synthesis of sources through the literary analysis were realized before building the IT artefact. Relatively, the system is an improvement of existing systems in the legal framework. On a holistic view, the project aims to enhance judicial processes through technology, which involves the facilitation of communication platforms, enabling file- 
sharing, and ascertain access to public services. Altogether, the project is built under the assumption that existing judicial systems are lacking in the mode of implementation of access to justice in the global legal framework considering the limitation of legal practitioners.

\subsection{Research Methods}

\subsubsection{Approach}

The research method involves an exploratory study, which is a qualitative approach. According to Chigbu (2019, pp. 1-2), a qualitative approach is about "the analysis and interpretation of textual or numerical data (or both) collected mostly from verbal (or textual) mediums to uncover meaningful patterns that describe a particular phenomenon, event, subject or object." Relatively, the approach intended to understand the technical factors that influence the applicability of information systems in the judicial system. Thus, the survey utilized assessed the level and manner in which participants interact with information systems.

Regarding ethical considerations, the study involved different participants, including judges, prosecutors, court clerks, lawyers, and the general public. Consequently, primary research accounted for ethical principles and cultural sensitivity, as stipulated by the universal laws of research. The researcher observed the informed consent guideline, which is a significant issue in conducting research. The informed consent involved introducing all participants to the study and stating its purpose and explaining the various aspects of research, including the procedures. The researcher further informed the participants about the benefits of the survey. Participants got a disclosure explaining all the measures taken to ensure confidentiality and anonymity as well as ensuring that no harm came to any participant.

\subsubsection{Survey Design}

The study adopted an online survey design involving two phases - one before the development of the IT artefact and another one after the development of the system. Based 
on the DOI theory, the study explored why and how litigants would choose to utilize the IT artefact of the communication system in the legal order. Also, the method of TRA helped to realize how the intentions of an individual affect their attitude towards technology. The initial section of the survey entailed straight forward questions and later narrowed down to specific questions that involved seeking explanations from participants. Censoring Touchette (2019), the questionnaire depends on four key components, which include writing questions that participants can understand and formulating questions that participants have the right information to answer. Other properties entail writing questions that participants can use their understanding to provide answers in the required format and formulating questions that participants are willing to answer.

The respondents who took part in all surveys were legal practitioners, court workers, litigants, and the general population with employment status. Since their response influenced the development of the IT artefact, respondents were selected anonymously, and their feedback kept private and confidential. The method was essential for limiting the possibility of any form of bias. Participants were all adults aged 19 years and above, and about 100 participants were engaged. However, a minimum of 45 participants was to take part in the surveys. Finally, the study utilized a general random sampling technique for data collection. However, samples primarily originated from participants with some background knowledge of legal matters. Survey questions were distributed to different respondents across the country through links sent to participants via email. The data collection process utilized the Google Forms tool.

\subsection{Design Considerations}

System analysis and design involve determining the functionalities of a computer-based information system as well as its needs (Liu and Eck, 2008). The breakdown occurs during the construction of a new system or redesigning an existing one, and there are several factors to consider during this phase. Through sensitivity analysis, parameters with the most considerable impact on the system are determined (Liu and Eck, 2008). The web-based IT 
artefact utilized an iterative system development life cycle (SDLC). The iterative nature of the SDLC was due to the limited time frame for design and development.

\subsubsection{System Requirements}

The requirements of the IT artefact developed in the dissertation include both functional and non-functional requirements. However, since any does not sponsor the project business organization, the information system was developed as a prototype for an academic endeavor. Therefore, the system requirements, in this case, translate to academic requirements or deliverables.

Table 2: System requirements for developing the IT artefact

\section{Type of Requirements Deliverables}

\section{Functional}

\section{Interactive Platform}

- $\quad$ The system must provide a communications platform where the judiciary can give legal information.

- $\quad$ The system must provide a communications platform where the public can access this information and interact with caseworkers.

- The system must allow users to chat with employees during video or audio conferencing.

2. File-sharing

- The system must enable file-sharing by the different types of users who will interact with the system. 
3.

\section{Access Control and Authentication}

- The system must ascertain controlled access to public services to users through the use of credential access.

Non-functional

- The system must develop a user-friendly communication platform in conjunction with intuitive design and layouts, as depicted in Figure 8.

\subsubsection{Use Cases}

The use case diagrams are essential, displaying the requirements in simple terms as they provide a high-level view of an information system. Use case diagrams - used to represent the use cases - only summaries some relationships between use cases, actors, and how they relate to the system. Also, the diagrams do not indicate clear steps used to achieve the objectives of the information system. Therefore, the use cases act as a visual representation of system activities and the users involved.

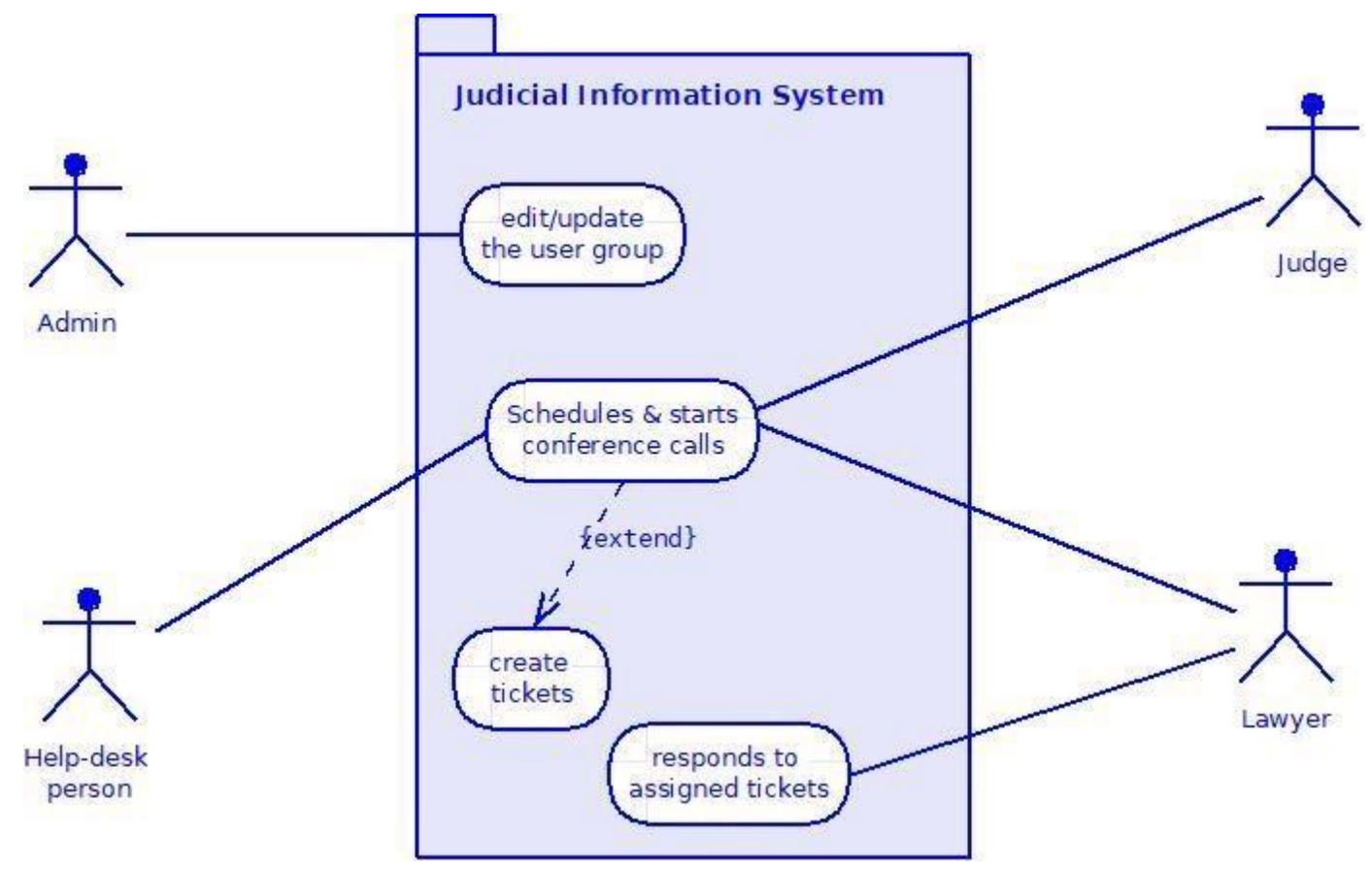

Figure 3: Use Case Diagram 


\subsubsection{System Design}

\subsubsection{System Architecture}

Components of the system prototype include a graphical user interface (GUI), file manager, database, human resource (HR) and procedures, and a chat manager. The information and data in the information system exist in the cloud. The cloud is not only secure but also offers limitless access to information. That is, through cloud-based systems, users can access legal documents or data at any time and from anywhere through their user accounts with a significant reduction in operational and management costs (Gonzalez, de Brito Carvalho, and Miers, 2017; Shen et al., 2014). The user can engage the web-based IT artefact through a GUI that allows them to access different services like file sharing. The HR and procedures co-ordinate the flow of activities and system resources.

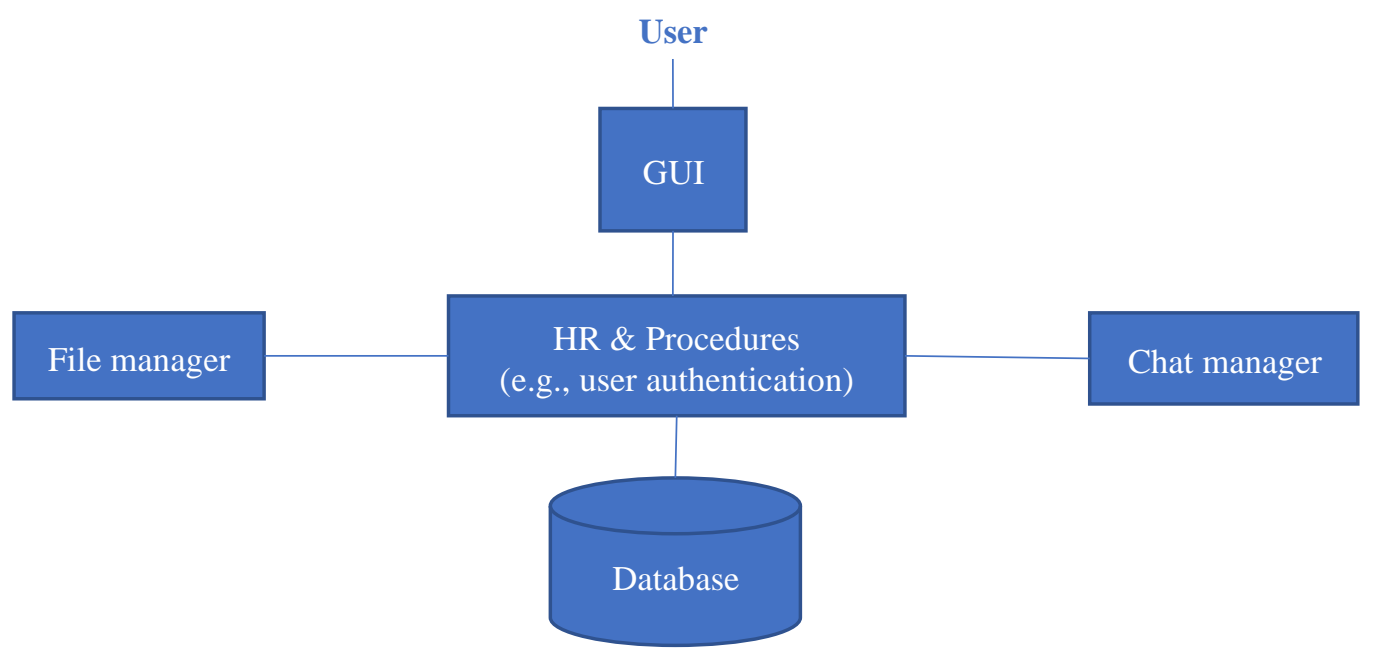

Figure 4: High-level diagram of system components

The system enables every user to identify themselves before accessing system resources like file sharing. For instance, to obtain legal documents, a litigant must have a registered account through which they can query information from the database courtesy of authentication procedures and managed through access control. Also, a litigant can interact with the HR that belongs to the specific state or community court through chat that offers instant messaging capabilities during video or audio conferencing. It is the HR team responsible for the coordination of any internet conferencing activities like videoconferencing and VolP. Also, users can share files - this is enabled through the file 
management system - with other litigants or lawyers or any legal practitioner altogether. Finally, a relational database is part of the development process with a specific focus on an open-source relational database management system called MySQL. A review of the database exists in the Appendix section.

\subsubsection{Evaluation Criteria}

Specific criteria were useful in the measurement of the success of the project. For the most part, the project aimed at designing a communication platform where the main functionalities include enabling credential access, video conferencing, file sharing, as well as chat functionalities. Accordingly, one of the criteria used to measure the success of the completed project is relevance, whereby the project assessment occurred in terms of the justification for designing the communication system. Another criterion was system efficiency, which determined the relationship of the output with the resources utilized. For instance, whether the chat functionalities result in any productive results with the public. Effectiveness was yet another essential criterion; the intended outcomes of the project revealed the extend and satisfactory levels of their achievements.

\subsection{Chapter Summary}

The chapter describes the research approach and design methodology adopted. The study applies an exploratory approach to understand the technical factors that influence the applicability of information systems in judicial systems. Additionally, the chapter outlines an analysis and design of the IT artefact and design presented as a working prototype and encompassed functional and non-functional requirements. Realizing the information system includes data collection from participants via online surveys and the development of both physical and conceptual design and testing the system. The next chapter portrays a further understanding of the IT artefact and research conduct and validation. 


\section{Chapter 4: IMPLEMENTATION (REALISATION)}

\subsection{Chapter Introduction}

The qualitative research method used in the study engages the two theories of technological acceptance: DOI and TRA. The two approaches were critical in the development process as they helped build awareness on factors that influence website users. This section depicts the realization of IT Artefact and research conduct and validation. The implementation consists of collecting data from participants through an online survey, development of both conceptual and physical architecture, and testing the system. The chapter also summarizes survey findings by focusing on specific themes through a holistic approach.

Detailed results of survey questions exist in the Appendix section.

\subsection{Details of the Implementation}

\subsubsection{Research Conduct and Validation}

Developing the prototype occurred after conducting the first survey - a pre-design survey. The selected participants were all adults who are employed and have a history with the court system. The link for the survey questions reached 100 respondents. However, some chose not to take part in the survey. Data from only 52 participants were part of the analysis. Data collection process occurred between 10th and 20th June 2020, with the issue of anonymity taken into strong consideration, as discussed in chapter 3 above. The questionnaire used is in the Appendix section. The method of data analysis utilized in this document is a content analysis that involves exploring both written comments in the survey and selected options such as Yes or No. Therefore, themes determined the coding method. 


\subsubsection{Pre-design Survey Results and Interpretation}

The significance of data analysis is that it provides room for interpretation and gaining insight for research questions and involves understanding of non-automated data that requires human examination and data processing through automation (Sutton and Austin, 2015). The presented survey results account for the research questions outlined in the first chapter of this document. The results were analyzed based on the following steps:

1. Data preparation and organization: this involves printing the digital copy of the survey results as well as organizing transcripts and notes and acknowledging any available demographics.

2. Review and exploration of the data: this is about reading the data to get a sense of its contents.

3. Creating initial codes: data coding helps the analyst connect with data.

4. Review and revision of the codes: this stage involves the identification of shared beliefs, opinions, or languages used to categories data.

5. Presentation of themes: themes that exist cohesively.

\subsubsection{Digital literacy}

Results imply that despite easy access to the internet, a significant percentage of the respondents hold reservations on a court's website efficiency when used for litigation purposes. The high percentage representing those who had difficulties when using a website indicates that future studies should establish the reasons and possible remedies. Also, if managing court websites and other online platforms occur appropriately, the belief of individuals may increase significantly. Accordingly, more than half of the respondents reported a low confidence level in the use of judicial websites.

\subsubsection{Impact of Technology}

The majority of the respondents, $75 \%$, stated they would accept video calls from strangers. 
This finding validates some of the litigants' low confidence in transacting and utilizing information derived from the internet. Results depict the prevalence of technology, most notably, video conferencing is high among various organizations in different levels of management as most organizations employ videoconferencing and VolP in administrative functions.

However, very few employees experience the use of such technologies in their organizations. The low experience rating from findings has more to do with the applicability of the conferencing technologies than their existence. Accordingly, some of the participants' recommendations were that the video conferencing should have easy-to-understand instructions for their customers. $94.2 \%$ of the respondents agreed to recommend video conferencing services to other organizations. This number shows that the impact of technology is affirmative. Also, $80.8 \%$ agreed that remote communication methods like video conferencing have the massive potential of replacing face-to-face communication. The high percentage proves the point that the impact of technology on individuals and organizations is assenting.

\subsubsection{Access to Justice (including access to courts)}

A survey on access to justice confirmed that only $32.7 \%$ of the participants could afford to hire a lawyer. The responses to this question indicate that one of the major hindrances to accessing justice is financial restraints. Also, $80.8 \%$ of participants affirmatively documented that cost can affect court trials. However, the fact that many courts can interpret hearings in the mother tongue to bridge the language barrier was very encouraging; this does not mean that the language barrier is not an issue in court hearings.

\subsubsection{Review of the Judicial System}

Based on the findings, very few people seek court registry services or case queries: $57.7 \%$ had not sought these services within the past year. The ones who use court registry services apply conventional means by going there in-person to solve their issues. Relatively, $25 \%$ of the participants had low confidence in the legal system, with $67.3 \%$ recording average confidence in the judiciary. As an improvement strategy, some 
respondents suggested that the long process be shortened and assigning more judges to different courts across the country to reduce caseloads. Altogether, the low level of satisfaction in the court system warrants extensive research on influential factors.

\subsection{The IT Artefact}

The software system prototype is to exhibit the functionalities of videoconferencing. An iterative SDLC model was used in the implementation process as it allowed short, frequent releases, and ease of change. The iterative model adopts initial and simplified implementation whereby the software is continuously improved during each review phase until the final complex system emerges. Relatively, more features were a requirement courtesy of the results obtained from the survey. According to Flora and Chande (2014), the iterative model is considered as a critical aspect of Agile Programming, enabling the build-up of small changes into a more substantial change.

Regarding the two theories of technological acceptance, DOI and TRA, the system was built to enables simplicity through an empathy map, which also relied heavily on survey feedback. An empathy map allows the visualization and articulation of user needs. According to McElroy (2016), the empathy map enables the creation of a shared understanding between the end-user and the user experience (UX) developer and also helps in decision making. Also, the relevance of the empathy map in the design process attributes to what users think, feel, say, and do (McElroy, 2016). Part of the demographic information utilized in the development of the IT artefact originated from the literature review conducted in this study. For instance, the possibility that most people have difficulty accessing legal information through court websites evokes the concept of a simple user interface. 


\subsubsection{Conceptual Architecture}

The web portal of the IT artefact functions like GotoMeeting and MS Teams. It has similar functionalities. The web portal has a ticketing system similar to (but not all the features of) Spiceworks helpdesk or Realengine Helpdesk. Highlights of the video conference include holding video/audio conference, users muting themselves, sharing files, chat capability, record session, shared screen, and end-to-end encryption. Further, system users include judges, lawyers, court workers, the help desk person, litigants, and the system administrator. However, anyone who wants to obtain information on the court's website does not have to be a litigant to do so; they have to sign up. Data associated with sign up includes gender, email, name, age, user's location, job title, social security number, and their company. As a system user, the judge is eligible for responding to assigned tickets and scheduling and starting conference meetings. A lawyer, on the other hand, can create tickets and schedule and starting conference meetings. The help desk person can schedule and start conference calls and update, close, or reassign all the assigned tickets. Finally, the system administrator updates user groups and handles user profiles as well as the tickets involved.

Altogether, the videoconferencing portal functions as follows;

1. Web portal with credentials where users can register

2. After registration users can create tickets

3. After ticket submission, the ticket will automatically forward to the helpdesk

4. Helpdesk can edit or send the ticket to the right person

5. The system can also allow multiple levels of staff groups

6. Users or staff can upload documents, videos, audio or comments to the ticket

7. Any update to the ticket the user will receive an email 
8. All staff can schedule a conference call and send out links to all necessary members

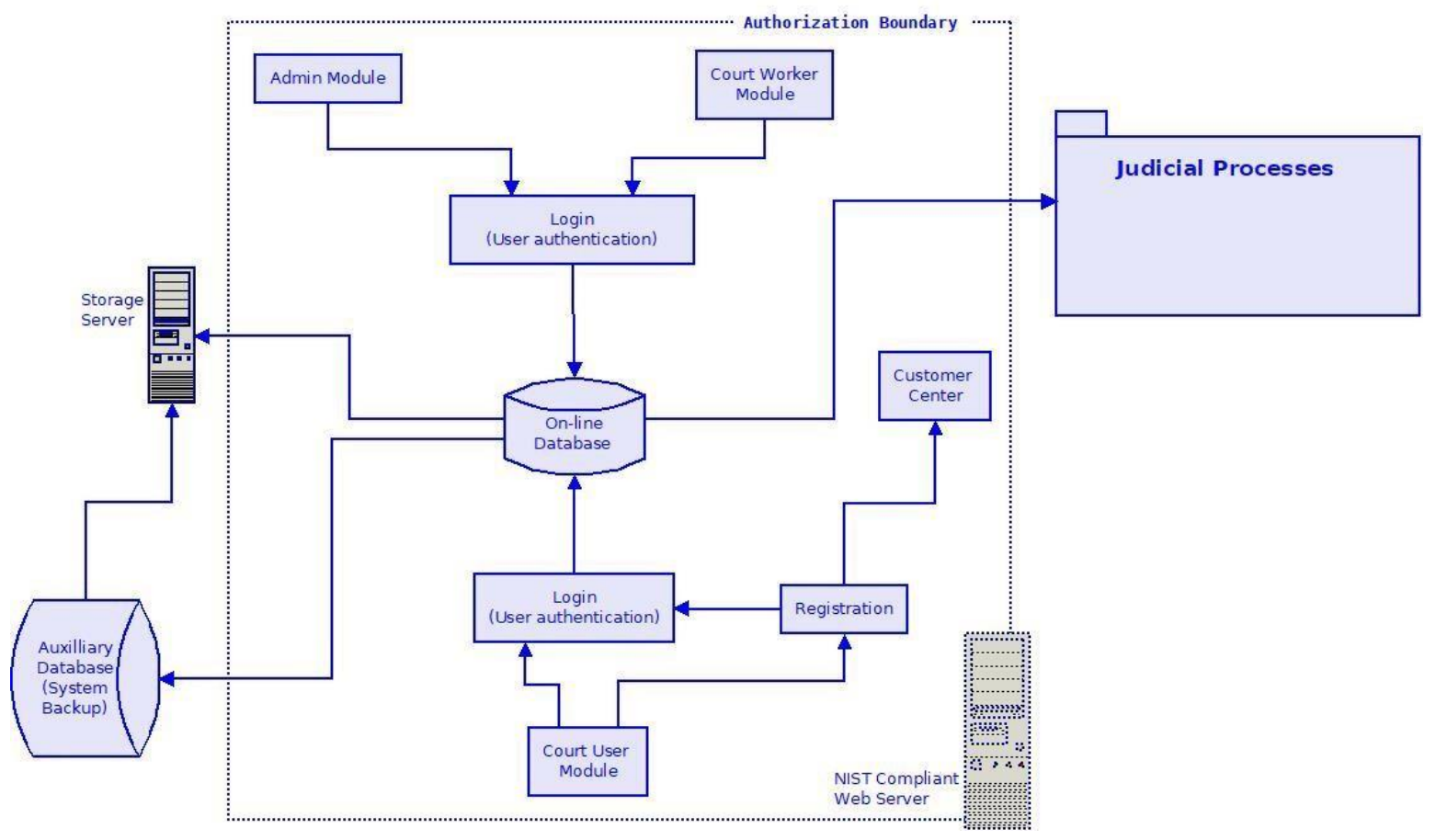

Figure 5: System architecture diagram

\subsubsection{Physical Architecture}

The videoconferencing system defined during the design phase executed using PHP Laravel, and the API for conference calls was from EnableX. The IT artefact also utilizes a MySQL relational database to permit data flow during process execution. During the initial phase of development, the database was installed on a physical machine. The essence of a physical machine was to prevent complications during access to the data layer. Windows 10 OS was used to develop the system before the entire site was hosted online, along with its dependencies. 
Table 3: $A$ list of the specifications for the desktop computer

\begin{tabular}{|l|l|}
\hline Component Description & Component Specification \\
\hline Processor & Intel(R) Core (TM) i7 CPU \\
\hline Number of cores & 6 \\
\hline Ram & $16 \mathrm{~GB}$ \\
\hline Architecture & 64 bits \\
\hline Hard disk capacity & $500 \mathrm{~GB}$ \\
\hline Operating system & Windows 10 \\
\hline
\end{tabular}

\subsubsection{Testing and Validation}

Testing and validation of the IT artefact occurred after mitigation to a cloud platform (webhosting). Validation involved four steps, the first being validation planning. Through the validation plan, it is possible to identify the parties influenced by the system and where it is applicable. The system should serve legal practitioners, litigants, and anyone who seeks legal information from the court website. The second step is the definition of system requirements, which is about determining what the system should accomplish and further breaks down into functional and infrastructure needs. The third step is the validation protocol and testing specification. System objectives, scope, risks, and software tests exist in this step. The test cases utilized identify events, inputs, and predictable responses to determine if system features function accordingly. Finally, testing marks the beginning of the actual examination. Relatively, the Black box testing (one that focuses on software inputs and outputs) is for system validation courtesy of test cases. The process involves testing for bugs, defects, or possible system failure. 


\section{Chapter Summary}

The chapter entails project implementation attained via data collection from participants through online surveys and the development of the physical and conceptual design of the IT artefact. Data collection involves adult employed participants with a history with the court system. Out of 100 participants, data from 52 participants underwent analysis. A questionnaire containing 23 open and closed-ended questions involved the participants with gender and age as demographic items. According to the survey, digital literacy focused on the theme of internet usage intending to determine the role of digital literacy in enhancing communication through legal information systems. Also, the technology segment section ascertained the effect of technology on the court system with judges and other court administrators being the beneficiaries. The part on access to justice assessed justice accessibility by identifying barriers in the legal framework with technology as a driving factor.

Chapter 4 also encompasses the analysis and interpretation of findings, which, collectively, provide a holistic perspective of the judicial information systems in practice. Therefore, the chapter details opinions from users that currently interact with court websites or similar technical applications on their day to day endeavors. Findings affirm that court websites and information systems consider the most vulnerable member of society's legitimate need to enhance equality and access to justice. Therefore, the ability to remotely access court services and legal aid ensures that the community's most vulnerable groups can access pro bono services omitting structural barriers that limited access to justice.

Feedback from participants is part of the evaluation of the IT artefact in Chapter 5 of this document. The implementation process accounts for the conceptual architecture of the IT artefact. The physical architecture utilizes a MySQL relational database to allow data flow during process execution. The system testing and validation comprise validation planning, the definition of system requirements, validation protocol and testing specification, and testing altogether, the next chapter provides an in-depth analysis of the working prototype predefined in the initial phase of the project. 


\section{Chapter 5: RESULTS AND EVALUATION}

\subsection{Chapter Introduction}

This chapter evaluates the IT artefact in great length. The rapid development of information and communication technology has significantly improved access to justice. Technological development involves new opportunities for access and administration of justice. In essence, technical systems are in use to address the increased number of self-represented litigants (SRLs). This dissertation involves the development of an information system software with a novel perspective to justice. The primary aim of the project is to realize a working legal information system that streamlines legal services to serve as a tool for the improvement of access to justice. The aim relies on the following objectives: the facilitation of a communications platform where the judiciary can provide legal information to the public, the development of a file-sharing and a chat interface for users, ascertain controlled access of public services by users.

\subsection{Evaluation of IT Artefact}

\subsubsection{Analysis of Results}

\subsubsection{Results Validation Process}

The pre-design survey involved demographic items placed on the initial section of the questionnaire to validate the legitimacy of the results obtained. Demographic questions were about age and gender. These two questions may have little impact on data interpretation and the overall significance of findings to the dissertation, but they should help eliminate possible bias. For instance, it would be less convincing if all the participants belonged to a single-gender or if they all belonged to the same age group. The demographic results indicate that respondents were from two genders, and a significant number from each gender took part in the survey. Out of the 52 participants, $71.2 \%$ were male, while $28.8 \%$ were female. Thus, it is worth noting that the considerable variation of gender 
participation may not equate to very few female employees in the judicial sector. Altogether, the demographic question only serves as a validator for the survey samples.

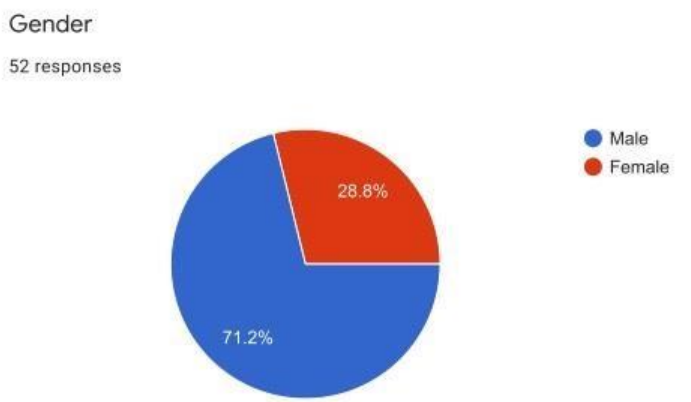

Figure 6: Demographic results - 1

The second demographic question - Age - depicts participants from five age groups based on the illustration. While the age of the majority of the respondents was between 19-25 years and 26-35 years, people aged 46 and above barely took part in the survey. Accordingly, the rest of the results are, therefore, reasonable as most people in the US labor force are millennials. Relatively, Desilver (2019) reveals that "Roughly a third of people in the labor force (35\%, or 56 million) are Millennials - those ages 23 to 38 in $2019 . "$ The Millenials surpassed generation Xers (ages 39 to 54 in 2019) in 2016 (Desilver, 2019). Respectively, the high number of millennials in the labor force, coupled with the increased use of technology in most businesses, suggests the high number of respondents aged between 19-35 years (78.9\%). Altogether, the second demographic qualifies as a validator of the samples. 


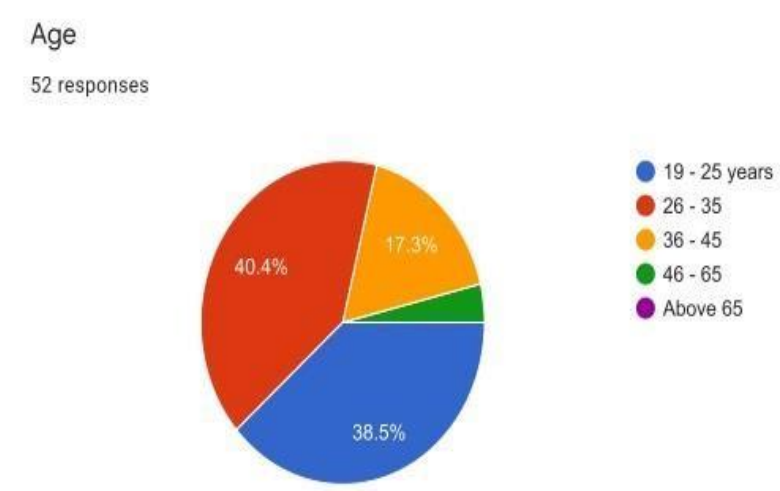

Figure 7: Demographic results - 2

On the other hand, the validity of the post-design survey results involved cleaning collected data through reverse coding. Reverse coding in this context means that the participant must provide consistent responses to negatively phrased questions relative to similar positively framed questions. For instance, survey data from the questionnaire applicable to court users suggests consistent results. Coding data from the third question (Do you think the system is more complicated than it should be?) and the fifth question (Do you need any technical support to use the system?) depicts consistency. That is, all participants who thought that the system is not complicated did not require any technical support to use the system. Therefore, reverse coding affirms that the results are dependable.

\subsubsection{Post-design Survey Results and Analysis}

The post-design survey included two categories of participants, namely court users like litigants and court workers like lawyers and court clerks. The number of participants for court users was ten while that for court employees was seven. $70 \%$ of court users said they have never used a similar court website in the past. Similarly, more than $85 \%$ of court employees also said they have never used a similar system in the past. Accordingly, the results present a rare system, which may offer new opportunities for both legal practitioners and litigants. Also, while $100 \%$ of court employees agreed that all system features are working accordingly, $100 \%$ of court users agreed that the system is user friendly since none of them needed any technical support to use the system. Altogether, the IT artefact has a user-friendly interface, which is an essential requirement of the project specified under the objectives of the study. 
The findings address the dissertation research question about how improved communication between the public and the judiciary can improve the effectiveness of service delivery. $80 \%$ of court users think that the system improves accessibility to court services. From a user's perspective, the United Nations Development Programme (UNDP) barriers of access to justice include a limited number of legal aid system and long delays (Velicogna, 2011). System users perceive the IT artefact to be efficient and effective, which means it may help improve communication in the judicial system to help address the issue of information overload covered under the problem statement of the dissertation. Based on findings by Velicogna (2011) and responses from the post-design survey, the IT artefact helps improve access to judicial services compared to the traditional court system.

Findings address the dissertation research question about the cost and time implications of the enhanced communication systems on the judiciary. All the participants involved in the post-design survey admitted that the system is time-saving. Also, $100 \%$ of court employees agreed that the information system is necessary for solving cost issues regarding legal services. Relatively, $100 \%$ of court users, through that the IT artefact may aid in reducing the cost of access to justice. Relatively, the traditional justice system is weakened by prohibitive costs of accessing judicial services, including the high cost of representation (Velicogna, 2011). For instance, fees for Public Access to Court Electronic Records (PACER) increase the cost of access to legal information (Marimow, 2020). Also, in 2016 alone, PACER fees in the United States were $\$ 146.4$ million (Marimow, 2020). The IT artefact addresses such costs by availing filings for free to all registered litigants and court users. The efficiency of judicial information systems may vary, but it fascinating how court users and legal practitioners perceive them as a solution to the cost issue. Altogether, with reduced time and cost of access to justice, litigants can finally enjoy the benefits of an enhanced communication system.

Another research question addressed by the IT artefact and the post-design survey findings involves whether the implementation of an enhanced communication system in the judiciary may enhance the geographic accessibility of the courts. Based on the 2019 Congressional Budget of the Judiciary, the Supreme Court of the United States recorded a projected 
increase in travel expenses from $\$ 667,000$ in 2017 to $\$ 1,094,000$ in 2019 (The Administrative Office of The U.S. Courts, 2018). The budget presents an example of issues that the IT artefact addresses regarding physical accessibility to court services. With a reduced cost of justice, the IT artefact serves as the basis for improved access to justice through a coherent information system that addresses the issue of geographical boundaries. For instance, $100 \%$ of court employees confirmed that the system could help improve the geographical accessibility of court services. In comparison, $80 \%$ of court users affirmed that the system improves accessibility to judicial services. Altogether, the IT artefact provides an avenue to address the issue of geographical boundaries allowing more people to benefit from legal services from anywhere over the internet.

Finally, the dissertation also sought to address the benefits and challenges associated with the implementation of an enhanced communication system for the judiciary. The benefits include an opportunity to experience judicial services from anywhere at any time and within a reasonable budget. A report by the World Justice Project (2019) reveals that most people do not turn to lawyers or courts whenever they experience legal problems due to accessibility issues. Out of the $29 \%$ who seek legal advice prefer to engage their family members or closes friends (World Justice Project, 2019). Such findings depict the absence of an enhanced communication system. Based on the survey results, one of the court users responded that "It will be great to have such as system, as of now it is really difficult to get information about your case, they have no system at all." Also, one of the court employees stated that "it can definitely ease up the legal proceedings." Accordingly, results from participants point out the benefits of an enhanced communication system in the judiciary. However, a significant challenge associated with implementing the information system was the time constraint. There was insufficient time to involve more participant reviews to improve the system further. 


\subsubsection{System Analysis and Design}

\subsubsection{System Verification}

The resulting IT artefact is an online information system in the form of a website accessible through computers, mobile phones, and tablets. Accordingly, responsive web design (RWD) resulted in an information system accessible and usable through multiple computing devices. Post-design survey results illustrated responsiveness in the IT artefact because all respondents reported no difficulty in navigating the system. Also, all participants said that the court website is not complicated. The interactive modules relate to the project objective that involves the development of a user-friendly communication platform achieved through intuitive design and layout. Accordingly, the intuitive plan and design adopted by the IT artefact encourage more users to engage the court website regarding most of their legal issues.

Another objective accomplished is to allow chat functionality. However, users have to create accounts by signing up then log into the system before using the chat feature. For instance, while booking an appointment, a litigant can chat with their respective legal practitioner. However, non-registered users can still access free consultations by sending a message to the support team or administrator using the 'Contact Us' message box. Therefore, the website offers an equal opportunity to potential court users as well as legal practitioners and litigants. Relatively, the system allows the administrator to view and edit user profiles as well as approve or delete users, including lawyers and judges. The management module of the administrator - which involves permissions, roles, and audit logs - corresponds to the objective of ascertaining controlled access to public services to users through the use of credential access.

Another successful objective of the project is the facilitation of a communications platform for the judiciary to provide legal information. For instance, layers judges, and some court workers like agents can create tickets and video conferences; this means that they can convey information to litigants through the court system. Also, the objective of the enabled file sharing is part of the functionalities of the IT artefact; this is part of a coherent system 
used to convey legal information effectively. Altogether, the system allows the public to access information and interact with caseworkers, creating an avenue for improved access to justice in the judicial domain.

The API framework used to develop the IT artefact is Laravel, which is an Open Source PHP development framework. The effectiveness and popularity of Laravel involve spending minutes on building functions that would typically require several hours of writing hundreds of codes (Stauffer, 2019). For instance, cache, which enhances performance as well as the user authentication module (Log in), pre-exist in the Laravel framework hence creating ease and efficiency during system development. The development of videoconferencing and audio (VoIP) utilized the EnableX API platform. The platform enables multiple real-time functionalities like one-to-one, one-to-many, and many-to-many real-time communication capabilities. Relatively, this allowed the integration of applications like browser-to-phone and browser-to-browser communication functionalities to the IT artefact. EnableX platform is easily accessible online.

Further, an Open Source Server-Side Language - PHP7 - was part of the programming languages applied as it supports a variety of large system applications. HTML, CSS, and JavaScript were essential for the Front-End Language. Finally, the IT artefact utilized DB MySQL - an Open Source database whose best performance involves data security, undemand scalability, high performance, and round-the-clock uptime.

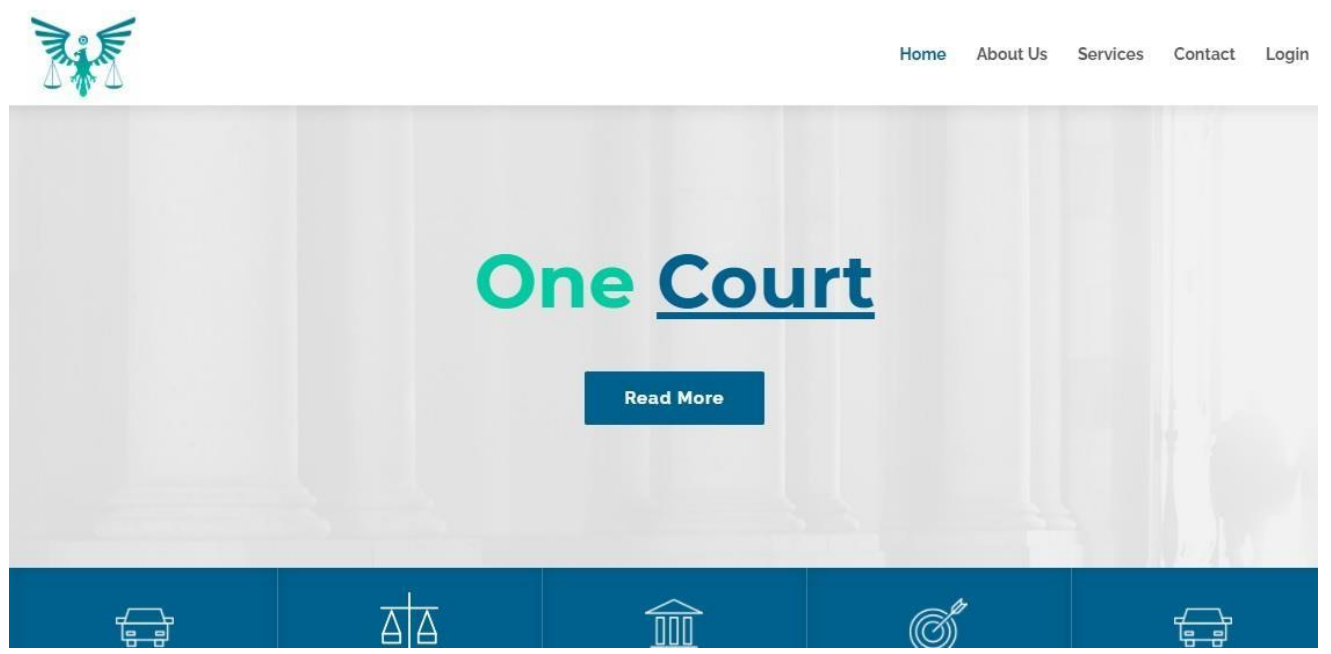

Figure 8: Home page of the court website 


\subsubsection{Testing and Validation}

Testing is an effective way of increasing user satisfaction, reducing risks, and ensuring the quality of the product. The validation process of the IT artefact involves a dynamic testing method to ensure that the system meets end-user requirements (Walden et al., 2015). Testing occurred in phases. For instance, the development stage involved unit testing, while the initial phase of the project included usability testing. The post-design survey helped in the usability testing process by involving both court users and legal practitioners. Therefore, post-design survey questions comprised themes essential in testing and validating system functionalities and requirements.

Moreover, the validation focused on the black box (functional) testing. The Laravel API framework eased unit testing during the development process through PHPUnit. According to Stauffer (2019), the integration of the PHPUnit (unit testing) feature in Laravel saves time for software testing: Laravel testing saves time to write unit tests. Also, since the agile methodology was part of the system development, multiple modules like chat functionality applied integration testing throughout the development process.

Lead testing occurred after the development of the IT artefact when it was fully functional. Load testing aims to ensure that the system can perform under real-life loads. The validation involved SoapUI - which is an Open Source web testing application - to test the RESTful API. The test plan for using SoapUl for load testing included the following respective procedures: Create a new Load Test, Run the Load Test, and Add Assertions to the Load Test. The process begins by creating a functional test case from an API definition - a formal description of the endpoints offered by the service - which in this case is a URL of the court website. During execution, the assertions validated the reception of a valid HTTP status code. The validation also ensures that response comes within a specific timeframe. Multiple test cases were selected: one for each endpoint described in the API definition. Test cases represent real-life user scenarios that involve numerous requests simulating a complete transaction. Test results should include both request data and response data after running the test case. 


\subsection{Chapter Summary}

Chapter 5 presents a detailed evaluation of the IT artefact as well as the role of both primary and secondary data in the design process. System verification aligns with the specific objectives of the project. The verification established that the system is of high quality, error free, and well-engineered with a particular focus on the objectives of the project. The effectiveness and efficiency of the system involved the specific criteria of measurement: measures based on the justification of system design. Process efficiency determined the relationship between input and output of resources, while effectiveness revealed the satisfactory levels of achieving expected outcomes. The analysis of results encompasses survey findings and aligns with the IT artefact. The testing approach used is the black box testing - system testing - to validate the system on the end-user perspective.

\section{Chapter 6: CONCLUSIONS}

\subsection{Chapter Introduction}

The underlying problem relates to population upsurge on a global scale that increases the demand for access to justice; this refers to the limited number of legal institutions that increase the cost of access to justice. This chapter presents significant lessons drawn from the project as well as its strengths and weaknesses. The conclusion accounts for the two theories of technology acceptance explored in the dissertation focusing on their relevance towards the development of the IT artefact. Also, the conclusion entails both academic and business applications and limitations of the research based on presented findings.

\subsection{Lessons Learned}

On a holistic view, significant learning outcomes about the topic revolve around limited access to justice due to the high demand for justice and the fact the most people can now access the internet and related technologies compared to the last decade. More specifically, the high cost of justice, lack of relevant legal information, the inability to 
interpret available legal knowledge, and the slow process of resolving legal issues are the primary factors that limit access to justice. However, all these problems link to the increased demand for justice due to the global population increase. For instance, the high cost of justice conforms to the laws of demand and supply: an increase in the need for legal services causes a corresponding increase in the charge for the services. Findings indicate that besides the cost of access to justice underrepresentation of litigants as a root cause of injustice is also a significant issue as most litigants lack the right avenues to access the correct legal information. That is, current judicial information systems require advanced technologies and innovations to reach a high number of litigants in pursuit of justice. For example, existing court websites can barely distinguish audiences, making it difficult for people without background on legal information to navigate the systems and access the information that they need.

Fortunately, another learning outcome, which links to the information age, places most litigants, and the majority of people in need of legal information in a better position to access justice through judicial information systems. Survey results demonstrate the possibility of transferring the fairest hearing and administrative services to online platforms to rule out the need for the physical presence of litigants and legal practitioners during the interaction. This new development attributes to the discovery that the dawn information age increased the number of internet literate people worldwide and that most people are comfortable and capable of using internet euchologies such as video conferencing to address legal matters. Relatively, the analysis of findings reveals that experts in the computing profession can leverage internet technologies such as teleconferencing to improve current information systems in the judicial domain.

\subsection{Strengths and Weakness of the Project}

The approach utilized in the project had its fair share of strengths and weaknesses. Current sources about the study area lack detailed information regarding the relevance and contribution of information systems towards access to administrative services; this was the 
basis of significant weaknesses regarding the synthesis of sources under the literature review. Therefore, the use of secondary findings to identify a practical solution to the problem was quite a challenge. Also, the fact that several courts still lack comprehensive information systems for resolving legal matters was a significant weakness as it presented uncertainties regarding what is best for court users. Further, limited literature on the success and failure of legal information systems increased the amount of time necessary for determining the best functionalities of the IT artefact for this project. Accordingly, improving the range and size of the study population could have helped fill the gap of limited literature by relying on more primary findings as to the basis of system design and development.

On the other hand, the strengths of the project involve the availability of simplified software development frameworks. The development framework aided in the design and development of an efficient and coherent IT artefact to address constitutional concerns online. For instance, the API framework used to build the IT artefact was Laravel, whose effectiveness involves spending minutes on building functions that would typically require several hours of writing hundreds of codes. The availability of simplified development tools eased the development, aiding in the design of a scalable information system that allows system changes without affecting current processes.

\subsection{Academic Application and Limitations}

This dissertation contributes to the field of research regarding the application of internet technologies such as videoconferencing and VolP services in legal information systems. The study aimed to streamline and enhance judicial processes through a coherent communication framework with a primary objective of improving access to justice. Both primary findings and findings from the review of secondary sources put together a body of information essential for addressing the issue of limited access to justice. The project presented a conceptual framework that involves system design-based bases on two theories of technology acceptance: TRA and the DOI. 
The major limiting factor of this project is that this study heavily relies on the synthesis of secondary data hence limiting the advantages of first-hand information. This issue attributes to the limited sample population used in the primary survey. Therefore, increasing the number of participants may help design a much better system. Also, the testing process was resource-intensive and very time consuming hence limiting the number of tests performed to verify and validate the information system. However, the number of tests performed serves a substantial role in ensuring system security and efficiency.

\subsection{Business Application and Limitations}

The business application of this project involves the theory of the TRA and the DOI. Subject to TRA, this study can determine the factors that influence online business transactions such as attitude and behavior. Based on the concept of DOI, this study can enhance company innovativeness through the creative ideas at company levels, and understanding variables like leadership, organizational structure, and external characteristics play a critical role in the range of innovations. Indubitably, the theory of DOI takes time to read multiple audiences or entities. As a result, the bounds of the business application of this study are TRA and DOI as theories of technology acceptance. The subjective norms, in this case, would be the constraints of access to justice the judicial system such as a limited number of legal practitioners, high costs of prosecution, and the low turnout of litigants due to conflicting time schedules. Also, big organizations have faced disruption and sometimes replacement by small organizations that are willing to adopt theories of technology acceptance, such as DOI. Thus, the diffusion of innovations, as the theory suggests, is dependent on how and why people and business entities are willing to apply new ideas or innovative technologies into their lives and current systems a limitation.

More succinctly, this dissertation project presents an IT artefact that serves as a prototype or information system template applicable in redesigning current judicial systems to improve access and administrative services. Therefore, legal firms may leverage the project in 
solving significant changes the impede coherence and effective communication within the legal framework through findings in this project, including the modules of the IT artefact.

\subsection{Recommendations and Prospects for Future Research}

Courts are increasingly employing communication technology and online information, thereby creating a need to study the consequences of such initiatives on the justice system. The inability of some economies to sustain the legal system with vast resources to meet the needs of every individual continues to drive a wedge between the rich and the poor in accessing justice. This situation should resolve if the judicial system is to experience any success in service delivery. Relatively, legal information systems should improve communication between the public and the judiciary to enhance the effectiveness of service delivery. If the practice is beneficial, judicial information systems must then improve the geographic accessibility of courts through reliable online presence. Adopting technology to access information within the legal service is necessary but requires a review of costs and time constraints of improving communication systems. The adjustments are essential to determine the benefits and challenges associated with the implementation of an enhanced judicial communication system.

The following recommendations should help realize a working legal information system that serves as a basis for possible improvements in the judicial system. First, the adoption of perceived control (PC) may enable litigants and legal practitioners to utilize internet technologies such as VolP and videoconferencing judicial information systems. PC would help improve the level of confidence of court users, including litigants. That is, if people believe in having an impact on a system, then they may as well trust the processes involved. Therefore, the PC should be an integral part of future judicial information systems. Secondly, a distinction between court users is an effective way to deliver the right information to the right audience rather than availing all public information to whoever needs it. For instance, the jargon user to avail legal information to the general population should differ from that used to address legal practitioners. Also, online presence matters a lot in 
informing litigants and any user of a court website, including those who are only interested in learning legal matters.

\subsection{Chapter Summary}

Chapter 6 is a summary of key findings and how they affect future works in the research area of judicial information systems and the legal framework altogether. The chapter explores significant learning outcomes, including the weaknesses and strengths exhibited by the project. Two theories of technology acceptance, TRA and DOI, help define both academic and business applications of the study. Altogether, the following recommendations should help serve as a source of improvement for future judicial information systems: the adoption of PC to improve the level of confidence of court users and the distinction between court users to deliver the right information to the right audience.

\section{REFERENCES CITED}

Anon. (2020) What is MoSCoW Prioritization? | Overview of the MoSCoW Method.

ProductPlan. Available at: https://www.productplan.com/glossary/moscow-

prioritization/ (accessed 14th May 2020)

Alban, D., Eynaud, P., Malaurent, J., Richet, J.L. and Vitari, C. (2019) Information Systems Management: Governance, Urbanization, and Alignment. John Wiley \& Sons.

Attaran, M. (2017) Cloud computing technology: leveraging the power of the internet to improve business performance. Journal of International Technology and Information Management, 26(1), pp.112-137.

Barendrecht, M., Kokke, M., Gramatikov, M., Porter, R., Frishman, M., and Morales, A. (2013) Impact assessment of the facilitadores judiciales programme in Nicaragua (No. 2013/113). WIDER Working Paper.

Barrett-Maitland, N. and Lynch, J. (2020) Social Media, Ethics and the Privacy Paradox. In Ethics, Laws, and Policies for Privacy, Security, and Liability. IntechOpen, pp.1-14. 
Bauer, A.T. and Ahooei, E.M. (2018) Rearticulating Digital literacy. Journal of Cyberspace Studies, 2(1), pp.29-53.

Bento, A. ed. (2012) Cloud Computing Service and Deployment Models: Lawyers and Management: Lawyers and Management. IGI Global.

Beqiraj, J. and McNamara, L. (2014) International Access to Justice: Barriers and Solutions (Bingham Centre for the Rule of Law Report 02/2014). International Bar Association.

Bhardwaj, R.K. (2019) Development of Online Legal Information System: Lawyers' Perceptions. DESIDOC Journal of Library \& Information Technology, 39(2).

Brescia, R.H., McCarthy, W., McDonald, A., Potts, K. and Rivais, C. (2014) Embracing disruption: How technological change in the delivery of legal services can improve access to justice. Alb. L. Rev., 78, p.553.

Cabral, J.E., Chavan, A., Clarke, T.M. and Greacen, J. (2012) Using technology to enhance access to justice. Harv. JL \& Tech., 26, p.241.

Calvert, C. and Bruno, J. (2010) When cleansing criminal history clashes with the first amendment and online journalism: Are expungement statutes irrelevant in the Digital Age. CommLaw Conspectus, 19, p.123.

Chigbu, U.E. (2019) Visually hypothesising in scientific paper writing: Confirming and refuting qualitative research hypotheses using diagrams. Publications, 7(1), p.22.

Coram, M. and Bohner, S. (2005) The impact of agile methods on software project management. In 12th IEEE International Conference and Workshops on the Engineering of Computer-Based Systems (ECBS'05) (pp. 363-370). IEEE.

Cortés-Mendoza, J.M., Tchernykh, A., Armenta-Cano, F.A., Bouvry, P., Drozdov, A.Y. and Didelot, L. (2016) Biobjective VolP service management in cloud infrastructure. Scientific Programming, 2016. 
Cortes, P. (2019) Using technology and ADR methods to enhance access to justice. International Journal of Online Dispute Resolution, 5(1), pp.103-121.

Desilver, D. (2019) 10 facts about American workers. Pew Research Center. Available at: https://www.pewresearch.org/fact-tank/2019/08/29/facts-about-american-workers/ (accessed 27th June 2020)

Durairaj, M. and Kannan, P. (2014) A study on virtualization techniques and challenges in cloud computing. International Journal of Scientific \&Technology Research, 1(1), pp. $147-151$.

Flora, H.K. and Chande, S.V. (2014) A systematic study on agile software development methodologies and practices. International Journal of Computer Science and Information Technologies, 5(3), pp.3626-3637.

Gonzalez, N.M., de Brito Carvalho, T.C.M. and Miers, C.C. (2017) Cloud resource management: towards efficient execution of large-scale scientific applications and workflows on complex infrastructures. Journal of Cloud Computing, 6(1), p.13.

Greacen, J.M. and Jones, W.L. (2013) Summit on the use of technology to expand access to justice: Analytical framework. Harvard Journal of Law \& Technology Occasional Paper Series.

Hackerson, D.K. (2010) Access to justice starts in the library: The importance of competent research skills and free/low-cost research resources. Me. L. Rev., 62, p.473.

High, R. (2012) The era of cognitive systems: An inside look at IBM Watson and how it works. IBM Corporation, Redbooks, pp.1-16.

Hou, Y., Lampe, C., Bulinski, M. and Prescott, J.J. (2017) Factors in Fairness and Emotion in Online Case Resolution Systems. In Proceedings of the $2017 \mathrm{CHI}$ Conference on Human Factors in Computing Systems (pp. 2511-2522). 
Kleinberg, J., Lakkaraju, H., Leskovec, J., Ludwig, J. and Mullainathan, S. (2018) Human decisions and machine predictions. The quarterly journal of economics, 133(1), pp.237-293.

Kumar, E.M. (2018) Cloud Computing in Resource Management. International Journal of Engineering and Management Research (IJEMR), 8(6), pp.93-98.

Lederer, F.I. (2018) Improving Access to Justice via Technology. ABA Journal: Defending Justice Series (online) (May 17, 2018). Available at: https://www.abajournal.com/news/article/improving_access_to_justice_via_technolog y (accessed 17th May 2020)

Liu, L. and Eck, J. (2008) Artificial crime analysis systems: Using computer simulations and geographic information systems. IGI Global

Loyle, C.E. and Binningsbo, H.M. (2018) Justice during armed conflict: A new dataset on government and rebel strategies. Journal of conflict resolution, 62(2), pp.442-466.

Marimow, A.E. (2020) Should the public pay a dime for access to court records? The Washington Post. Available at: https://www.washingtonpost.com/local/legalissues/should-the-public-pay-a-dime-for-access-to-courtrecords/2020/02/02/578fa48842d1-11ea-b5fc-eefa848cde99_story.html (accessed September 1, 2020)

Marinescu, DC (2013) Cloud Computing: Theory and Practice Solutions to Exercises and Problems.

McElroy, K. (2016) Prototyping for designers: Developing the best digital and physical products. "O'Reilly Media, Inc."

Moxley, L. (2015) Zooming Past the Monopoly: A Consumer Rights Approach to Reforming the Lawyer's Monopoly and Improving Access to Justice. Harv. L. \& Pol' y Rev., 9, p.553. 
Oduntan, G. (2018) Access to justice in international courts for indigent states, persons and peoples. Indian Journal of International Law, 58(3-4), pp.265-325.

Palos-Sanchez, P.R., Arenas-Marquez, F.J. and Aguayo-Camacho, M. (2017) Cloud computing (SaaS) adoption as a strategic technology: Results of an empirical study. Mobile Information Systems, 2017.

Prescott, J.J. (2017) Improving Access to Justice in State Courts with Platform Technology. Vand. L. Rev., 70, p.1993.

Ranger, S. (2018) What is cloud computing? Everything you need to know about the cloud explained. ZDNet (online) (December 13, 2018). Available at: https://www.zdnet.com/article/what-is-cloud-computing-everything-you-need-to-know from-public-and-private-cloud-to-software-as-a/ (accessed 20th May 2020)

Rostain, T. (2019) Techno-Optimism \& Access to the Legal System. Daedalus, 148(1), pp.93-97.

Salter, S. and Thompson, D. (2016) Public-Centered Civil Justice Redesign: A Case Study of the British Columbia Civil Resolution Tribunal. McGill J. Disp. Resol., 3, p.113.

Sarkar, S. (2012) The role of information and communication technology (ICT) in higher education for the 21st century. Science, 1(1), pp.30-41.

Schetzer, L., Mullins, J. and Buonamano, R. (2002) Access to justice and legal needs: A project to identify legal needs, pathways and barriers for disadvantaged people in NSW. Law and Justice Foundation of New South Wales, 16, p.37.

Sela, A. (2018) Can Computers Be Fair: How Automated and Human-Powered Online Dispute Resolution Affect Procedural Justice in Mediation and Arbitration. Ohio St. J. on Disp. Resol., 33, p.91. 
Shen, Y., Li, Y., Wu, L., Liu, S. and Wen, Q. (2014) Enabling the New Era of Cloud Computing: Data Security, Transfer, and Management. Information Science Reference.

Silverman, B.G., Hanrahan, N., Huang, L., Rabinowitz, E.F. and Lim, S. (2016) Artificial intelligence and human behavior modeling and simulation for mental health conditions. In Artificial Intelligence in Behavioral and Mental Health Care (pp. 163183). Academic Press.

Silverman, J. (n.d) How the Judicial System Works. HowStuffWorks. Available at: https://people.howstuffworks.com/judicial-system.htm (accessed 5th June 2020)

Soltanian, A., Belqasmi, F., Yangui, S., Salahuddin, M.A., Glitho, R. and Elbiaze, H. (2018) A cloud-based architecture for multimedia conferencing service provisioning. IEEE Access, 6, pp.9792-9806.

Staudt, R.W. and Medeiros, A.P. (2012) Access to justice and technology clinics: a 4\% solution. Chi.-Kent L. Rev., 88, p.695.

Stauffer, M. (2019) Laravel: Up \& Running: A Framework for Building Modern PHP Apps. O'Reilly Media.

Sun, L., Mkwawa, I.H., Jammeh, E. and Ifeachor, E. (2013) Guide to voice and video over IP: for fixed and mobile networks. Springer Science \& Business Media.

Sutton, J. and Austin, Z. (2015) Qualitative research: Data collection, analysis, and management. The Canadian journal of hospital pharmacy, 68(3), p.226.

Talebian, S., Mohammadi, H.M. and Rezvanfar, A. (2014) Information and communication technology (ICT) in higher education: advantages, disadvantages, conveniences, and limitations of applying e-learning to agricultural students in Iran. Procedia-Social and Behavioral Sciences, 152, pp.300-305.

The Administrative Office of The U.S. Courts. (2018) The Judiciary Fiscal Year 2019 Congressional Budget Summary. United States Courts. Available at: 
https://www.uscourts.gov/sites/default/files/fy_2019_congressional_budget_summary _final_0.pdf (accessed September 1, 2020)

Theodoridis, A., Ragkos, A. and Salampasis, M. eds. (2019) Innovative Approaches and Applications for Sustainable Rural Development: 8th International Conference, HAICTA 2017, Chania, Crete, Greece, September 21-24, 2017, Selected Papers. Springer.

Thompson, D. (2015) Creating New Pathways to Justice Using Simple Artificial Intelligence and Online Dispute Resolution. IJODR, 2, p.4.

Touchette, A., (2019), How to Create Effective Research Surveys. Medium. Available at: https://medium.com/knowledgenudge/how-to-create-effective-researchsurveysc282f134beb3 [accessed June 5, 2020]

Trafimow, D. (2009) The theory of reasoned action: A case study of falsification in psychology. Theory \& Psychology, 19(4), pp.501-518.

Trepte, S., Teutsch, D., Masur, P.K., Eicher, C., Fischer, M., Hennhöfer, A. and Lind, F. (2015) Do people know about privacy and data protection strategies? Towards the "Online Privacy Literacy Scale" (OPLIS). In Reforming European data protection law (pp. 333-365). Springer, Dordrecht.

van Hoorn, A. (2014) Model-driven online capacity management for component-based software systems. BoD-Books on Demand.

Velicogna, M. (2011) Electronic access to justice: From theory to practice and back. Droit et cultures. Revue internationale interdisciplinaire, (61).

World Justice Project. (2019) Global Insights on Access to Justice. World Justice Project. Available at: https://worldjusticeproject.org/sites/default/files/documents/WJP-A2J2019.pdf (accessed September 1, 2020) 
Walden, D.D., Roedler, G.J., Forsberg, K.J., Hamelin, R.D. and Shortell, T.M. (2015) INCOSE Systems Engineering Handbook: A Guide for System Life Cycle Processes and Activities. John Wiley \& Sons.

Warren, E. (2018) Legal, ethical, and professional issues in information security. Retrieved 31st January. (pp. 89-116)

Wolf, M.J. (2012) Collaborative technology improves access to justice. NYUJ Legis. \& Pub. Pol'y, 15, p.759.

Zaaiman, J. and Leenan, L. eds. (2015) Iccws 2015-The Proceedings of the $10^{\text {th }}$ International Conference on Cyber Warfare and Security: ICCWS2015. Academic Conferences Limited.

Zeleznikow, J. (2016) Can artificial intelligence and online dispute resolution enhance efficiency and effectiveness in courts? In IJCA (Vol. 8, p. 30). 